\title{
Finite element formulation and algorithms for unsaturated soils. Part II: Verification and application
}

\author{
Daichao Sheng ${ }^{1, *, \dagger}$, David W. Smith ${ }^{1}$, Scott W. Sloan ${ }^{1}$ and Antonio Gens ${ }^{2}$ \\ ${ }^{1}$ Discipline of Civil, Surveying \& Environmental Engineering, The University of Newcastle, NSW 2308, Australia \\ ${ }^{2}$ Civil Engineering School, Technical University of Catalonia (UPC), Barcelona, Spain
}

\begin{abstract}
SUMMARY
The finite-element formulation and integration algorithms developed in Part I are used to analyse a number of practical problems involving unsaturated and saturated soils. The formulation and algorithms perform well for all the cases analysed, with the robustness of the latter being largely insensitive to user-defined parameters such as the number of coarse time steps and error control tolerances. The efficiency of the algorithms, as measured by the CPU time consumed, does not depend on the number of coarse time steps, but may be influenced by the error control tolerances. Based on the analyses presented here, typical values for the error control tolerances are suggested.

It is also shown that the constitutive modelling framework presented in Part I can, by adjusting one constitutive equation and one or two material parameters, be used to simulate soils that expand or collapse upon wetting. Treating the suction as a strain variable instead of a stress variable proves to be an efficient and robust way of solving suction-dependent plastic yielding. Moreover, the concept of the constitutive stress is a particularly convenient way of handling the transition between saturation and unsaturation. Copyright (C) 2003 John Wiley \& Sons, Ltd.
\end{abstract}

KEY WORDS: unsaturated soils; finite element method; constitutive model; stress integration; time integration

\section{INTRODUCTION}

In Part I [8], a finite-element formulation for geotechnical problems involving saturated and unsaturated soils is presented. The emphasis of this formulation is on simplicity and ease of implementation, but without sacrificing the essential features of unsaturated soil behaviour. In forming the global governing equations, only mechanical and hydraulic processes are considered. The stress-strain constitutive relations are formulated in such a way that both unsaturated and saturated soil behaviour can be modelled in a consistent way. To achieve this, the suction is treated as a strain variable instead of a stress variable.

Part I also presents an adaptive time-stepping scheme for solving the discretized global equations which govern the deformation and fluid flow in saturated and unsaturated soils. The key feature of this scheme is that it automatically adjusts the time-step size so that the time-

\footnotetext{
*Correspondence to: Daichao Sheng, Discipline of Civil, Surveying and Environmental Engineering, The University of Newcastle, NSW 2308, Australia.

${ }^{\dagger}$ E-mail: Daichao.Sheng@newcastle.edu.au
} 
stepping error in the displacements lies close to a specified tolerance. This property removes the need to determine the time-stepping error by an empirical trial-and-error procedure. An explicit stress integration scheme is also presented to solve the resulting local constitutive equations. This is based upon the modified Euler method with automatic subincrementation and error control [1,2]. The difference between a first-order-accurate Euler solution and a second-orderaccurate modified Euler solution is taken as the local error measure and is then used to subincrement the given strain increments. In generalizing this scheme to cover unsaturated soil behaviour, special attention is given to the suction-dependent plastic yielding. In line with the treatment of the suction as a strain component, the elastoplastic stiffness matrix in the Euler solution is evaluated using the suction (as well as the stresses and hardening parameters) at the start of the subincrement while the elastoplastic matrix in the modified Euler solution is evaluated using the suction at the end of the subincrement. In addition, when subincrementing, the same rate is applied to all strain components (including the suction).

The finite-element formulation and algorithms presented in Part I have all been implemented in the funite-element code, SNAC, developed at the University of Newcastle, Australia, over the last decade. This code is used for all examples in this paper.

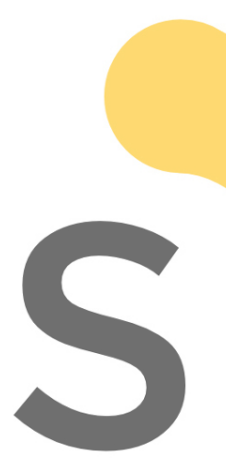

\section{CONSTITUTIVE RELATIONS AND MATERIAL PARAMETERS}
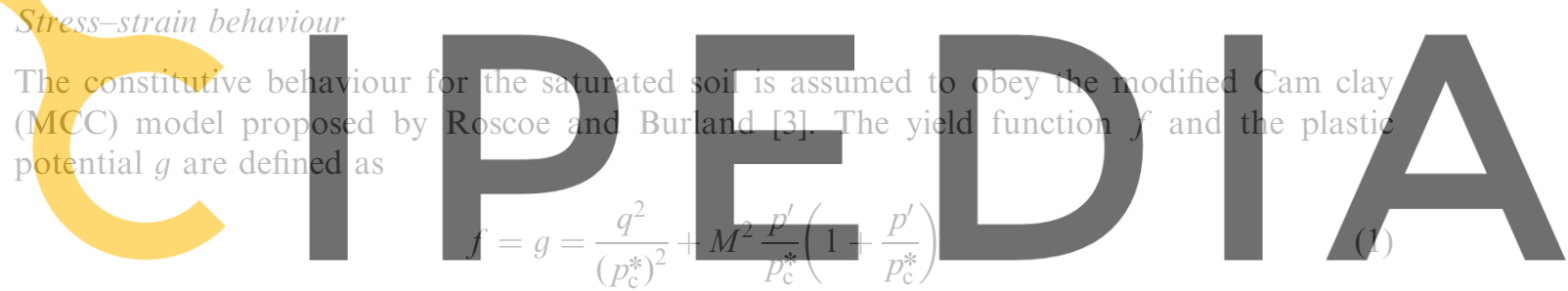

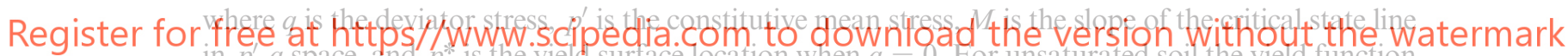
in $p^{\prime}-q$ space, and $p_{\mathrm{c}}^{*}$ is the yield surface location when $q=0$. For unsaturated soil the yield function is of the same form as Equation (1), but $p_{\mathrm{c}}^{*}$ is assumed to vary with the suction according to

$$
\frac{p_{\mathrm{c}}^{*}}{p_{\mathrm{r}}}=\left(\frac{p_{\mathrm{c}}}{p_{\mathrm{r}}}\right)^{\left(\lambda_{0}-x\right) /(\lambda-x)}
$$

where $p_{\mathrm{c}}$ is the yield surface location at zero suction and is also the hardening parameter, $p_{\mathrm{r}}$ is a reference mean stress and is set to 1 in this paper, $\lambda_{0}$ is the slope of the normal compression line (NCL) for saturated soil, $\lambda$ is the slope of the NCL for unsaturated soil, and $x$ is the slope of the unloading-reloading line (URL) and is assumed to be independent of suction. Equation (2) is similar to the Barcelona basic model (BBM) of Alonso et al. [4], except that the mean stresses are constitutive stress instead of net stress. The slope $\lambda$ is assumed to vary with suction according to

$$
\lambda= \begin{cases}\lambda_{0}\left((1-r) \exp \left(-\beta u_{\mathrm{w}}\right)+r\right) & u_{\mathrm{w}}>\frac{u_{\mathrm{w} 2}}{\beta} \\ \lambda_{0}\left(\left(0.875+\sqrt{0.015625-\left(\beta u_{\mathrm{w}}-u_{\mathrm{w} 1}\right)^{2}}\right)(1-r)+r\right) & \frac{u_{\mathrm{w} 1}}{\beta}<u_{\mathrm{w}} \leqslant \frac{u_{\mathrm{w} 2}}{\beta} \\ \lambda_{0} & u_{\mathrm{w}} \leqslant \frac{u_{\mathrm{w} 1}}{\beta}\end{cases}
$$


where $r$ and $\beta$ are two material parameters. Note the parameter $r$ is dimensionless, while the units of $\beta$ are the inverse of suction, e.g. $(\mathrm{kPa})^{-1}$. Equation (3) is a smoothed version of the function given by Alonso et al. [4]. The two dimensionless parameters $u_{\mathrm{w} 1}$ and $u_{\mathrm{w} 2}$ smooth both $\lambda$ and its derivative $\partial \lambda / \partial u_{\mathrm{w}}$. Their exact values can be obtained by matching the derivative with respect to $u_{\mathrm{w}}$ at the transition points

$$
\begin{aligned}
& u_{\mathrm{w} 1}=-0.05111961064754801 \\
& u_{\mathrm{w} 2}=+0.03567832315393903
\end{aligned}
$$

The yield surface location at zero suction, $p_{\mathrm{c}}$, defines the hardening parameter (as in the BBM model) and the hardening law is described as

$$
\mathrm{d} p_{\mathrm{c}}=\frac{v p_{\mathrm{c}}}{\lambda_{0}-x} \mathrm{~d} \varepsilon_{\mathrm{v}}^{\mathrm{p}}
$$

where $v$ is the specific volume and $\varepsilon_{\mathrm{v}}^{\mathrm{p}}$ is the plastic volumetric strain. The elastic behaviour of the model is described by the relations

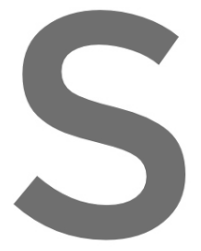

$$
\mathrm{d} p^{\prime}=\frac{v p^{\prime}}{x} \mathrm{~d} \varepsilon_{\mathrm{v}}^{\mathrm{e}}=K \mathrm{~d} \varepsilon_{\mathrm{v}}^{\mathrm{e}}
$$

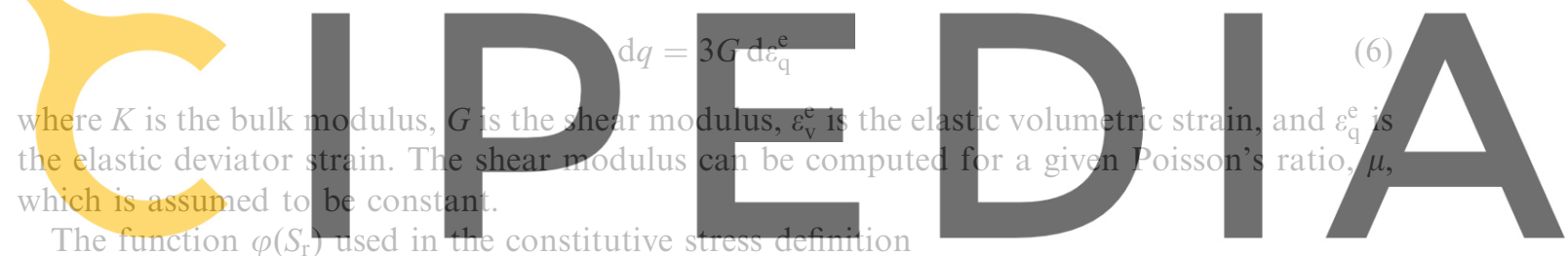

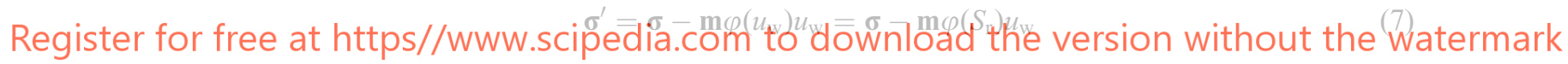

is related to the degree of saturation which is in turn related to the suction. To eliminate the need for a material parameter for the constitutive stress function, this function is set to either $\varphi=S_{\mathrm{I}}$ or $\sqrt{S_{\mathrm{r}}}$ in the problems analysed here. The use of these alternatives will be discussed when specific problems are analysed.

There are seven material parameters involved in the mechanical relations:

- $M$-slope of the critical state line, dependent on the friction angle at critical state,

- $\mu$-Poisson's ratio,

- $\lambda_{0}$-slope of the NCL for saturated soil,

- $x$-slope of URL for saturated and unsaturated soil,

- $N$-specific volume of the NCL when $p^{\prime}=1$,

- $r$-parameter for determining $\lambda$ for given suction, see Equation (3),

- $\beta$-parameter for determining $\lambda$ for given suction, see Equation (3).

\section{Soil-water characteristics}

In the finite-element formulation of Part I, the degree of saturation is expressed as a function of the suction and the permeability varies with the degree of saturation. Here we assume that the 
former function is given by the van Genuchten [5] relationship

$$
S_{\mathrm{r}}=\frac{1}{\left(1+\left(u_{\mathrm{w}} / a\right)^{b}\right)^{c}}
$$

where $a, b$ and $c$ are material parameters. In this equation, the degree of saturation and its derivative with respect to the suction are continuous at $u_{\mathrm{w}}=0$.

Permeability of unsaturated soils

The permeability is assumed to be related to the suction according to the Hillel [6] expression

$$
k=k_{\mathrm{s}} S_{\mathrm{r}}^{m}
$$

where $m$ is a material parameter and $k_{\mathrm{s}}$ is the permeability for saturated soil.

In total, the soil-water characteristics (8) and permeability (9) thus require five material parameters: $a, b, c, m$ and $k_{\mathrm{s}}$. Together with the seven parameters in the stress-strain equations, there are 12 material parameters in the model examined here.
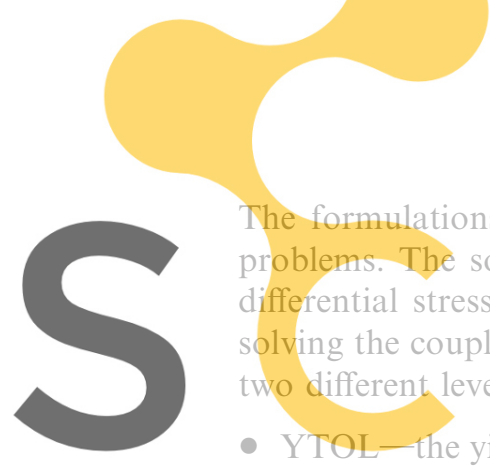

\section{APPLICATIONS}

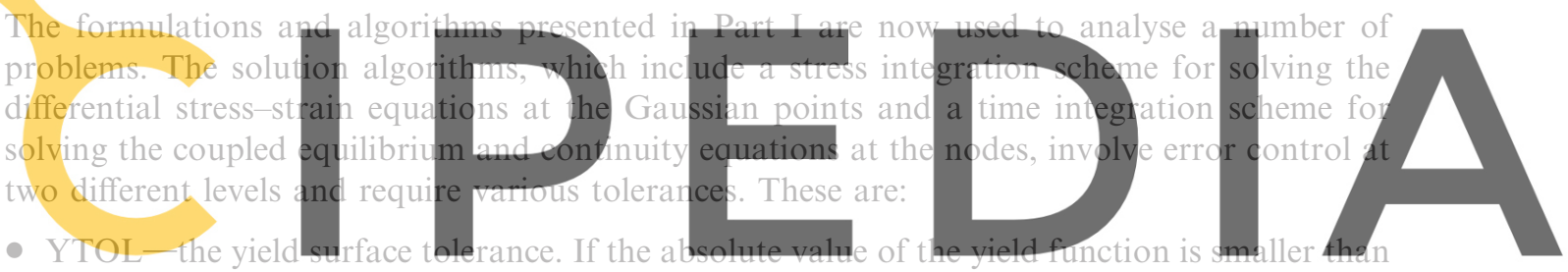

YTOL, the stress state is considered to be located on the yield surface.

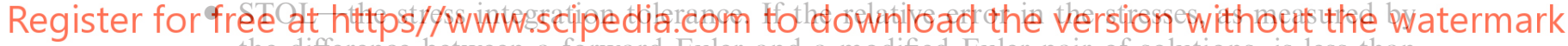
the difference between a forward Euler and a modified Euler pair of solutions, is less than STOL, the stress integration for the current strain subincrement is considered to be successful. This results in the modified Euler stresses and hardening parameters being accepted and the solution is advanced to the next strain substep.

- ITOL-the Newton-Raphson iteration tolerance. If the unbalanced force norm (normalized with respect to the external force norm) is smaller than ITOL, the Newton-Raphson iteration process is deemed to have converged for the current load step.

- DTOL - the displacement error tolerance. If the maximum relative error, computed as the difference between first-order-accurate and second-order-accurate solutions for the displacements and pore pressures, is less than DTOL, the time integration for the current time substep is considered to be successful. This results in the first-order-accurate displacements and pore pressures being accepted and the solution is advanced to the next load substep.

Unless stated otherwise, the present analyses assume the yield surface tolerance YTOL is set to $10^{-9}$, the stress integration tolerance STOL is set to $10^{-6}$, the Newton-Raphson iteration tolerance ITOL is set to $10^{-5}$, and the displacement error tolerance DTOL is set to $10^{-3}$. Note that these tolerances should not be set independently, as the quantities they control are related. For example, the stress integration error affects the yield surface error and, thus, setting STOL smaller than YTOL makes little sense as it will not always improve the stress integration 
accuracy. In the stress integration scheme, the maximum number of strain subincrements allowed per strain increment is set to 1000 . In the Newton-Raphson iteration for the velocities, the maximum number of iterations allowed per time substep is set to 50 . There is no limit imposed on the number of the time substeps per coarse time step.

All problems analysed in this paper use the unsaturated constitutive model presented in the previous section. The elements used are quadratic triangles with six displacement nodes and three pore pressure nodes.

All CPU times presented in this section are for a Pentium III $700 \mathrm{MHz}$ processor with 256 MB RAM.

\section{Triaxial tests}

Drained compression tests at different suctions. The first set of examples deals with drained compressive triaxial tests at different suctions. A soil specimen of $2 \mathrm{~cm}$ in radius and $8 \mathrm{~cm}$ in height is discretized into eight triangular six-noded axisymmetric elements. The material parameters are assumed to be

$$
\begin{aligned}
& M=0.772, \quad \mu=0.3, \quad \lambda_{0}=0.25, \quad x=0.05, \quad N=3.0, \quad r=0.75, \quad \beta=0.012\left(\mathrm{kPa}^{-1}\right) \\
& a=10(\mathrm{kPa}), \quad b=0.5, \quad c=1.0, \quad m=2.0, \quad k_{\mathrm{s}}=10^{-8}\left(\mathrm{~m} \mathrm{~s}^{-1}\right)
\end{aligned}
$$

and the constitutive stress parameter is set as $\varphi=S_{\mathrm{r}}$.

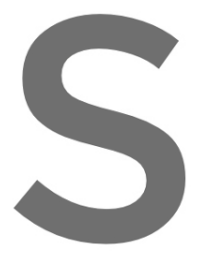

The initially saturation unloacled to $20 \mathrm{kPa}$ then slowly applied equal to the applied maintained at $20 \mathrm{kP}$ suction, the specime is
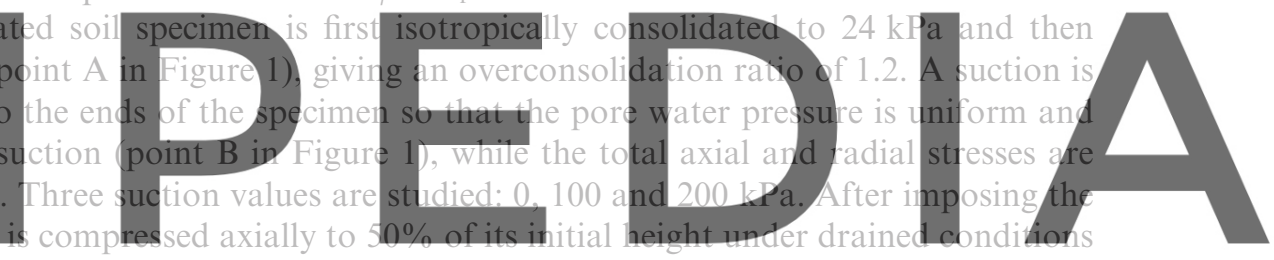

(point C in Figure 1), with the total radial stress and pore pressure at the ends remaining

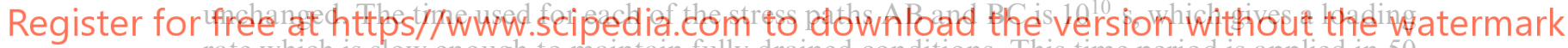
rate which is slow enough to maintain fully drained conditions. This time period is applied in 50 equal coarse increments which, if necessary, are subincremented automatically by the time integration scheme.

The predicted deviator stress is plotted against the axial strain in Figure 2, which shows that the shear strength increases as the soil becomes drier. Raising the suction from 0 to $100 \mathrm{kPa}$

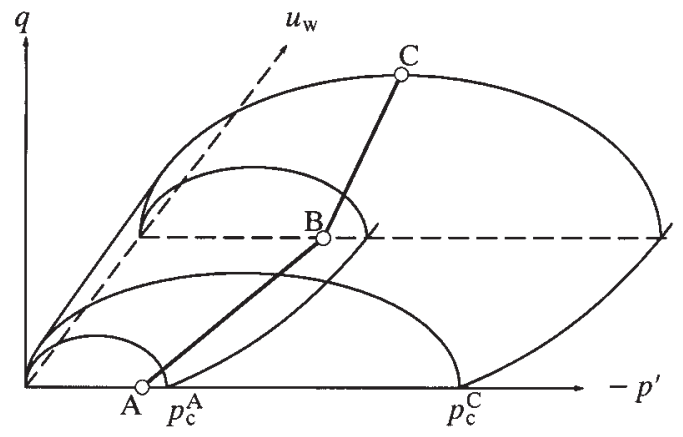

Figure 1. Stress path in triaxial compression tests at different suctions. 


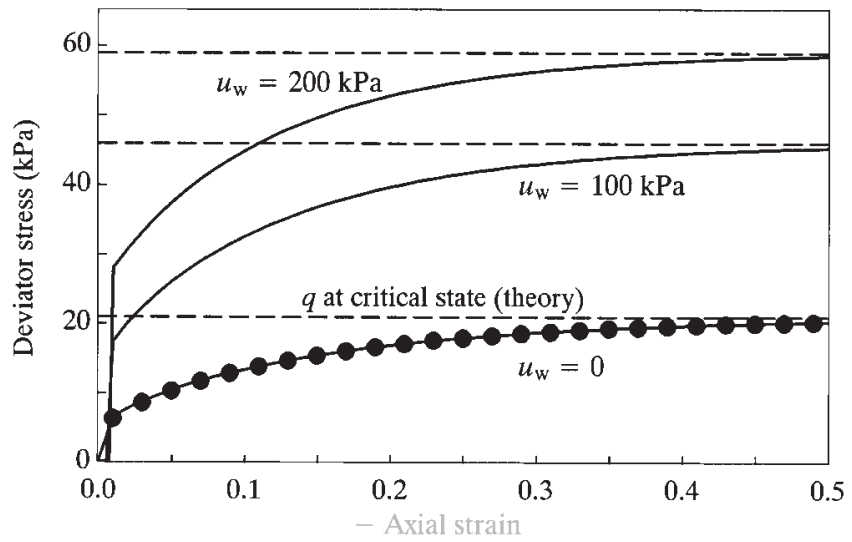

Figure 2. Predicted stress-strain curves (the dashed horizontal lines are analytical deviator stresses at critical state; the dots are results for dry soil in uncoupled analysis).

results in the deviator stress at the end of the tests increasing by $55 \%$ from 20.09 to $45.11 \mathrm{kPa}$. When the applied suction is further increased to $200 \mathrm{kPa}$, the final deviator stress is $58.27 \mathrm{kPa}$. For a triaxial test with a various initial stress states, the deviator stresses at the critical state can

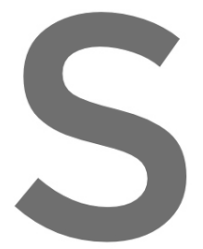
be found analyticall deviator stresses at triaxial test with zer analysis should be specimen. The latter, analysis results, with a maxi and are plotted as the d:
$0 \%$ axial strain agree
suction $\left(u_{\mathrm{W}}=0\right)$, the res
dentical to those
shown by the dotted curv
a maxinum discrepancy

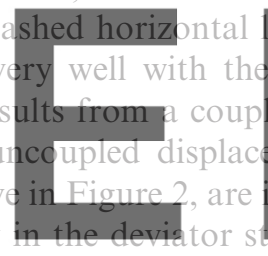
ines in Frgure 2. The
se values. For a fully
led displacdment-pore
ement analysis with a
indeed very close to th
ress of less than 0.070 predicted
drained
a dry spil
coupled

The variation of suction with $p^{\prime}$ and $q$ for these triaxial tests are shown, respectively, in

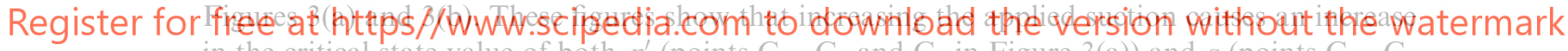
in the critical state value of both $p^{\prime}$ (points $\mathrm{C}_{1}, \mathrm{C}_{2}$ and $\mathrm{C}_{3}$ in Figure $3(\mathrm{a})$ ) and $q$ (points $\mathrm{C}_{1}, \mathrm{C}_{2}$ and $\mathrm{C}_{3}$ in Figure 3(b)). The exact values of $q$ and $p^{\prime}$ at the critical state can be found analytically and are indicated by the CSL line in Figure 3(c). The numerical values for $q$ and $p^{\prime}$ at an axial strain of $50 \%$ are very close to this line. The relationship between the specific volume and the constitutive mean stress, plotted in Figure 3(d), shows that triaxial compression at higher suctions causes a smaller volume decrease. This is due to the fact that drying to different suctions leads to different overconsolidation ratios (OCRs) for an unsaturated soil. As the suction increases, the constitutive mean stress increases at a different rate to the preconsolidation pressure, depending upon the parameters $r, \beta$ and $\varphi$. This is clear when we look at the initial yield surface location (YLD0) in the $p^{\prime}-u_{\mathrm{w}}$ diagram of Figure 3(a). The OCR of the soil, which is initially small at zero suction, increases with increasing suction. As the OCR increases, the soil becomes stiffer and thus experiences less plastic volumetric strain. It should be pointed out that the volume change characteristics shown here are associated with the particular values of $r, \beta$ and $\varphi$. Indeed, it is possible to adjust these parameters so that the constitutive stress increases faster than the preconsolidation pressure as the suction increases. In this case, drying would cause plastic deformation.

The influence of the various error control tolerances on the performance of the stress and time integration schemes are summarized in Table I for the triaxial test case with $u_{\mathrm{w}}=100 \mathrm{kPa}$. In all 

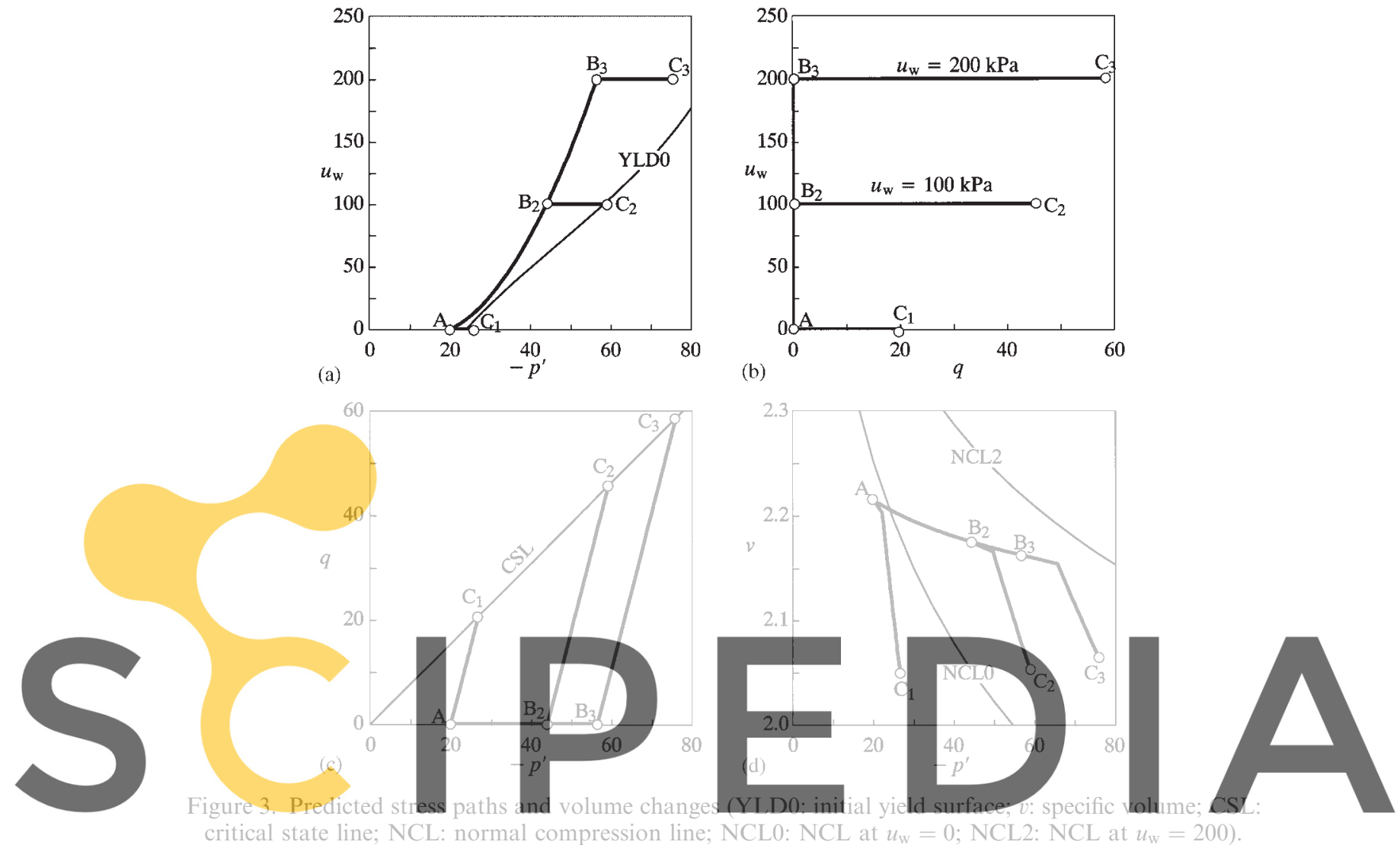

Register for free at https//www.scipedia.com to download the version without the watermark

runs, the yield surface tolerance is fixed at YTOL $=10^{-9}$. When studying the behaviour of the stress integration scheme, the displacement and iteration tolerances used in the adaptive timestepping scheme are set to DTOL $=10^{-3}$ and ITOL $=10^{-4}$, while the stress error tolerance, STOL, is varied from $10^{-1}$ to $10^{-6}$.

As expected, the data in Table I show that the maximum number of strain substeps (per time substep) increases as the stress tolerance STOL is decreased. Due to the nature of the stress error control, which subincrements the strains in proportion to the square root of STOL, the maximum number of strain subincrements should increase by a factor of roughly $\sqrt{10}$ if STOL is reduced by an order of magnitude. For runs with STOL smaller than $10^{-2}$, this is observed to be the case. For elastic deformation along the stress path $\mathrm{AB}$ in Figure 1, no strain subincrementation is needed. Decreasing STOL by four orders of magnitude, from $10^{-2}$ to $10^{-6}$, increases the CPU time required to integrate the stresses along the path $\mathrm{BC}$ by a factor of 5 , but has little effect on the number of time subincrements that are generated at the global level.

To study the effect of the displacement error tolerance DTOL, which attempts to control the global time-stepping error, it was varied from $10^{-1}$ down to $10^{-4}$ while STOL and ITOL were fixed at $10^{-6}$ and $10^{-2}$, respectively. The number of time substeps generated is not especially sensitive to DTOL, until it reaches a value of around $10^{-4}$. This merely reflects the fact that the 
Table I. Numerical statistics for triaxial tests with $u_{\mathrm{w}}=100 \mathrm{kPa}$.

\begin{tabular}{|c|c|c|c|c|c|c|c|}
\hline \multirow[t]{2}{*}{ Tolerances } & & \multicolumn{2}{|c|}{ CPU time (s) } & \multicolumn{2}{|c|}{ Total time substeps } & \multicolumn{2}{|c|}{$\begin{array}{l}\text { Max strain substeps per } \\
\text { time substep }\end{array}$} \\
\hline & & $\mathrm{AB}$ & $\mathrm{BC}$ & $\mathrm{AB}$ & $\mathrm{BC}$ & $\mathrm{AB}$ & $\mathrm{BC}$ \\
\hline $\begin{array}{l}\text { DTOL }=10^{-3} \\
\text { ITOL }=10^{-4}\end{array}$ & $\begin{array}{l}\text { STOL }=10^{-1} \\
\text { STOL }=10^{-2} \\
\text { STOL }=10^{-3} \\
\text { STOL }=10^{-4} \\
\text { STOL }=10^{-5} \\
\text { STOL }=10^{-6}\end{array}$ & $\begin{array}{l}1 \\
1 \\
1 \\
1 \\
1 \\
1\end{array}$ & $\begin{array}{l}1 \\
1 \\
1 \\
1 \\
3 \\
5\end{array}$ & $\begin{array}{l}55 \\
55 \\
55 \\
55 \\
55 \\
55\end{array}$ & $\begin{array}{l}80 \\
80 \\
79 \\
79 \\
79 \\
79\end{array}$ & $\begin{array}{l}1 \\
1 \\
1 \\
1 \\
1 \\
1\end{array}$ & $\begin{array}{c}1 \\
1 \\
3 \\
9 \\
27 \\
87\end{array}$ \\
\hline $\begin{array}{l}\text { STOL }=10^{-6} \\
\text { ITOL }=10^{-4}\end{array}$ & $\begin{array}{l}\text { DTOL }=10^{-1} \\
\text { DTOL }=10^{-2} \\
\text { DTOL }=10^{-3} \\
\text { DTOL }=10^{-4}\end{array}$ & $\begin{array}{l}1 \\
1 \\
1 \\
4\end{array}$ & $\begin{array}{l}5 \\
5 \\
5 \\
5\end{array}$ & $\begin{array}{c}50 \\
51 \\
55 \\
209\end{array}$ & $\begin{array}{l}50 \\
66 \\
79 \\
125\end{array}$ & $\begin{array}{l}1 \\
1 \\
1 \\
1\end{array}$ & $\begin{array}{c}134 \\
119 \\
87 \\
71\end{array}$ \\
\hline $\begin{array}{l}\text { STOL }=10^{-6} \\
\text { DTOL }=10^{-3}\end{array}$ & $\begin{array}{l}\text { ITOL }=10^{-3} \\
\text { ITOL }=10^{-4} \\
\text { ITOL }=10^{-5} \\
\text { ITOL }=10^{-6}\end{array}$ & $\begin{array}{l}1 \\
1 \\
2 \\
2\end{array}$ & $\begin{array}{c}4 \\
5 \\
7 \\
10\end{array}$ & $\begin{array}{l}55 \\
55 \\
55 \\
55\end{array}$ & $\begin{array}{l}77 \\
79 \\
79 \\
79\end{array}$ & $\begin{array}{l}1 \\
1 \\
1 \\
1\end{array}$ & $\begin{array}{l}96 \\
87 \\
84 \\
84\end{array}$ \\
\hline
\end{tabular}
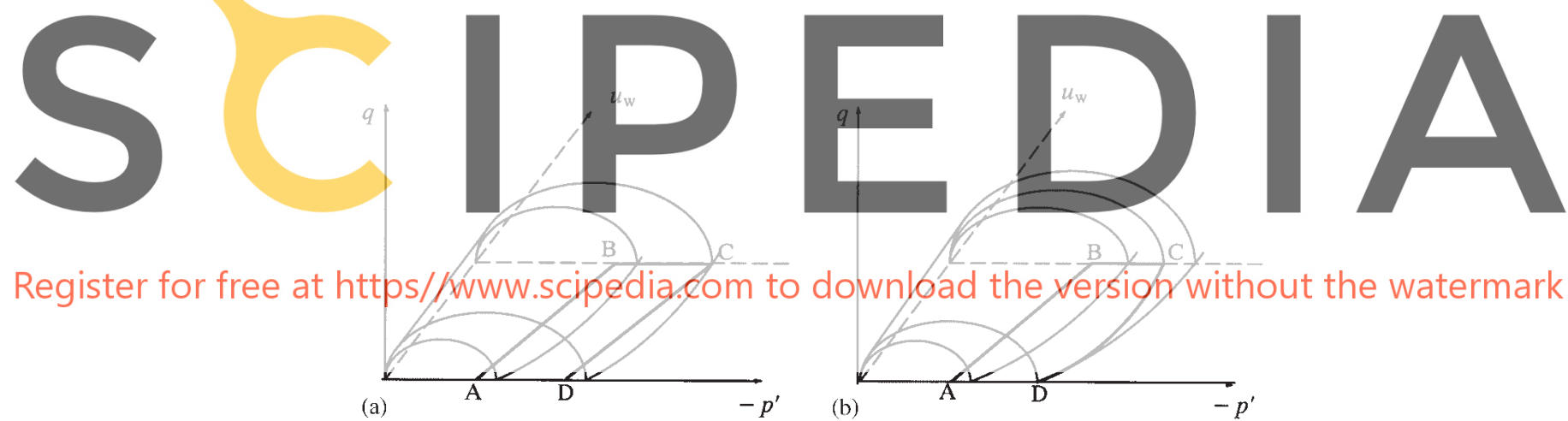

(a)

Figure 4. Stress paths in drying-wetting test: (a) elastic wetting; (b) elastoplastic wetting.

time integration error with 50 coarse load steps is quite small. Due to the generation of smaller load steps, the maximum number of strain subincrements per substep decreases with decreasing DTOL.

Varying the iteration tolerance ITOL from $10^{-3}$ down to $10^{-6}$, while keeping STOL and DTOL fixed at values of $10^{-6}$ and $10^{-3}$, has a negligible effect on the generation of the time and strain subincrements. It does, however, significantly increase the CPU time due to the extra iterations that are performed during each time substep.

Suction controlled drying and wetting tests: elastic and elastoplastic wetting. In this example, the soil is first dried to a given suction level, then isotropically compressed to yielding and then wetted to full saturation. The stress path is indicated in Figure 4. The wetting path from $\mathrm{C}$ to $\mathrm{D}$ 
can be elastic or elastoplastic, depending on how the yield surface location $p_{\mathrm{c}}^{*}$ and the constitutive mean stress $p^{\prime}$ vary as the suction decreases. If $p_{\mathrm{c}}^{*}$ decreases faster than $p^{\prime}$ as $u_{\mathrm{w}}$ is reduced, the wetting path $\mathrm{CD}$ will cause elastoplastic deformation. On the other hand, if $p_{\mathrm{c}}^{*}$ decreases more slowly than $p^{\prime}$ as $u_{\mathrm{w}}$ decreases, the wetting from $\mathrm{C}$ to $\mathrm{D}$ will only give rise to elastic deformation. Therefore, by adjusting the material parameters in Equations (3) and (7) or (8), it is possible to simulate both cases. We shall also demonstrate that the elastic wetting will cause dilatancy and the elastoplastic wetting will cause contraction.

For the case of elastic wetting, the constitutive stress parameter is defined as $\varphi=\sqrt{S_{\mathrm{r}}}$ and the other material parameters are assumed to be

$$
\begin{array}{llll}
M=0.772, & \mu=0.3, \quad \lambda_{0}=0.25, & x=0.1, & N=3.0, \quad r=0.9, \quad \beta=0.012\left(\mathrm{kPa}^{-1}\right) \\
a=10(\mathrm{kPa}), \quad b=0.5, \quad c=1.0, & m=2.0, & k_{\mathrm{s}}=10^{-8}\left(\mathrm{~m} \mathrm{~s}^{-1}\right)
\end{array}
$$

The initially saturated soil is first isotropically consolidated to $50 \mathrm{kPa}$ and unloaded to $20 \mathrm{kPa}$ (point A), giving an $\mathrm{OCR}=2.5$. Keeping the total radial and axial stresses fixed, the soil specimen is dried by applying a suction of $100 \mathrm{kPa}$ at both ends (point $\mathrm{B}$ ). The dried specimen is then isotropically consolidated again by applying a cell stress increment of $40 \mathrm{kPa}$ (point C), with the suction in the soil held constant at $100 \mathrm{kPa}$. This cell stress increment will cause plastic yielding of the soil. Finally, the specimen is wetted by reducing the suction at the ends to zero (point D). The time used for each of the stress paths AB, BC and CD is $10^{10} \mathrm{~s}$, which means that
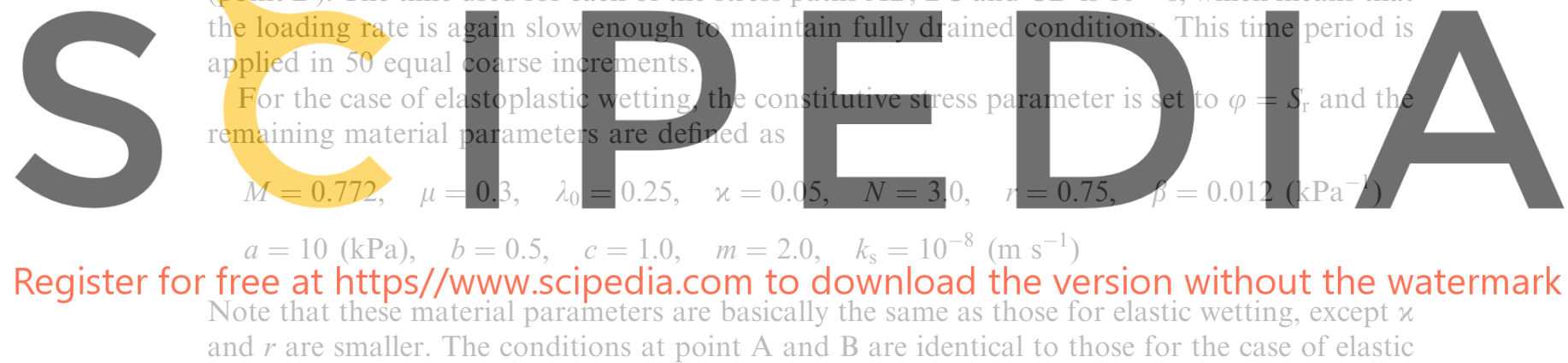

wetting and are obtained in the same way. However, point $\mathrm{C}$ is obtained by applying a cell stress increment of $240 \mathrm{kPa}$, with the suction in the soil held constant at $100 \mathrm{kPa}$. Such a cell stress increment causes approximately the same amount of plastic yielding in moving from point $\mathrm{B}$ to $\mathrm{C}$ in Figures 5(a) and 5(c). Finally, the specimen is wetted by reducing the suction at the ends to zero to obtain point $\mathrm{D}$.

The numerical results for these two cases are shown in Figure 5. For elastic wetting, the elastic stress path $\mathrm{AB}$ is followed by the elastoplastic path $\mathrm{BC}$ and then the elastic path $\mathrm{CD}$ (Figure 5(a)). The yield surface stays at $\mathrm{YLD}_{\mathrm{A}}$ when the soil is dried from $\mathrm{A}$ to $\mathrm{B}$, but moves to $\mathrm{YLD}_{\mathrm{C}}$ when the soil is isotropically compressed from B to $\mathrm{C}$, and stays there when the soil is wetted from $\mathrm{C}$ to $\mathrm{D}$. We note that as the suction changes, the constitutive mean stress changes faster than the yield surface size (preconsolidation pressure). The stress path $\mathrm{CD}$ is very close to the yield surface $\mathrm{YLD}_{\mathrm{C}}$, but always inside it. The volume change behaviour, shown in Figure 5(b), indicates that drying from A to B causes only elastic contraction as the path merely follows the URL. The isotropic compression from B to C causes both elastic and elastoplastic contraction, with the path first following the URL and then the normal compression line (for a suction of $100 \mathrm{kPa}$ ). The wetting from $\mathrm{C}$ to $\mathrm{D}$ causes purely elastic contraction and thus the path 

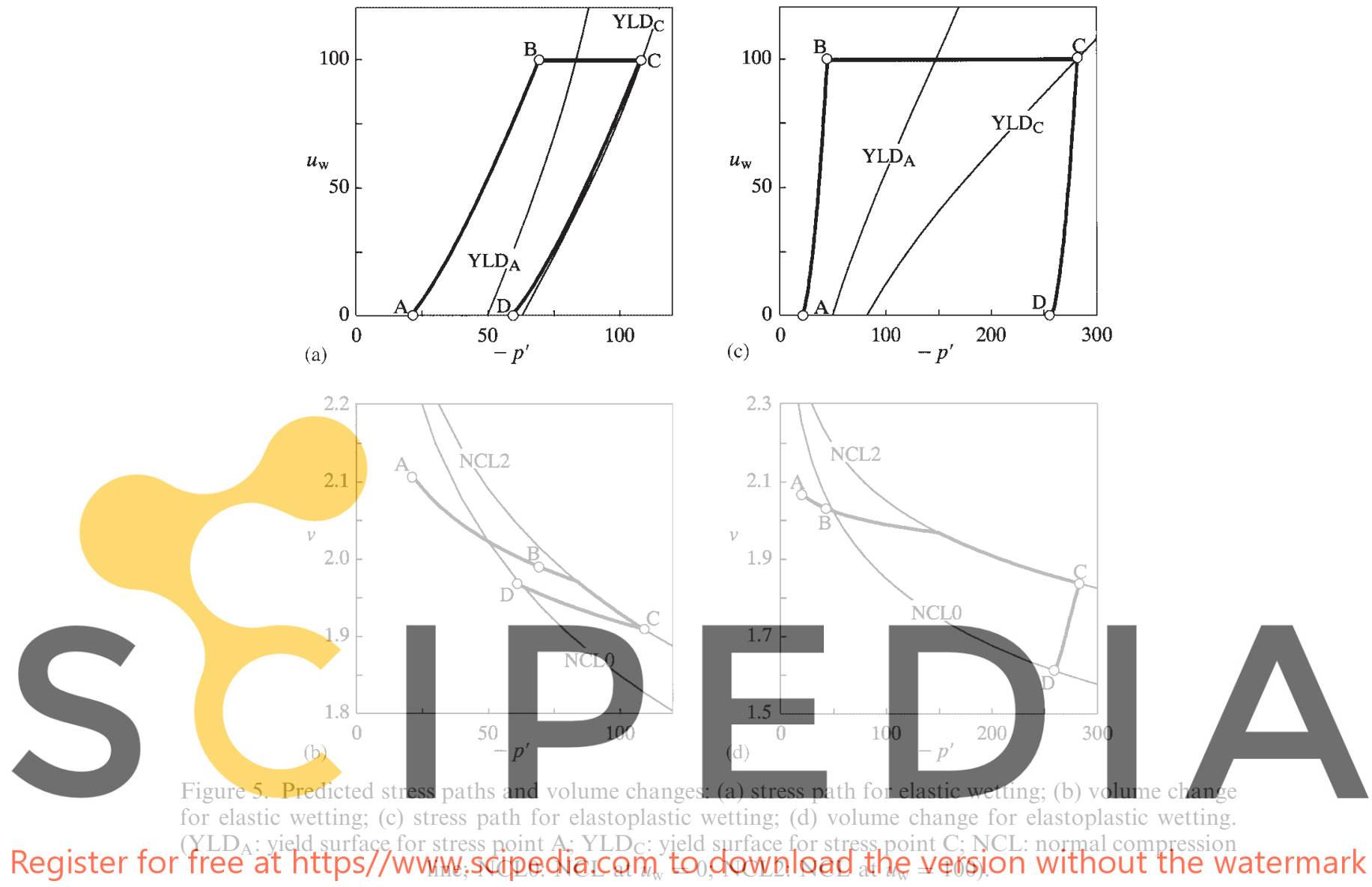

again follows the URL. We also see that the wetting phase causes elastic volume expansion, a mode of behaviour which is typical of expansive soils.

For the elastoplastic wetting case, the constitutive mean stress increases at a slower rate than the yield surface size (preconsolidation pressure) as the suction is increased from zero to $100 \mathrm{kPa}$ along the path $\mathrm{AB}$ (Figure 5(c)). This gives rise to purely elastic deformation. Holding the suction constant at $100 \mathrm{kPa}$ and increasing the cell pressure by $240 \mathrm{kPa}$ causes the yield surface to expand along the path $\mathrm{BC}$. Yield surface expansion also occurs as the suction is reduced to zero by wetting along the path $C D$. Note that the yield surfaces $Y_{L D}$ and $Y L D_{C}$ are nonconvex in Figure 5(c). The volume change during this wetting phase, depicted in Figure 5(d), shows a characteristic which is typical of collapsible soils, namely plastic contraction (or plastic collapse).

The above example demonstrates that the constitutive model is capable of predicting some basic aspects of expansive and collapsible soil behaviour, namely wetting-induced elastic expansion of expansive soils and wetting-induced elastoplastic collapse of collapsible soils. It is not, however, capable of modelling wetting-induced elastoplastic expansion. 
The numerical performance of the time stepping and stress integration algorithms is similar to the previous triaxial example and will not be discussed here. The results shown above are for analysis with YTOL $=10^{-9}, \mathrm{STOL}=10^{-6}$, ITOL $=10^{-5}$ and DTOL $=10^{-3}$.

\section{Footing}

Rigid footing at different suctions. We now consider the problem of a smooth rigid strip footing, of width $B$, resting on an elastoplastic soil layer. The mesh of six-noded triangles and boundary conditions for the various analyses are shown in Figure 6. To simulate the behaviour of a rigid foundation, the footing is subjected to a set of uniform vertical displacements and an equivalent pressure is computed by summing the appropriate vertical nodal reactions. Before applying these displacements, the nodes at the top boundary (the ground surface) are dried to different suction values. Because of the singularity at the footing edge and the strong rotation of the principal stresses during loading, this problem is a challenging test for the numerical algorithms presented in Part I.

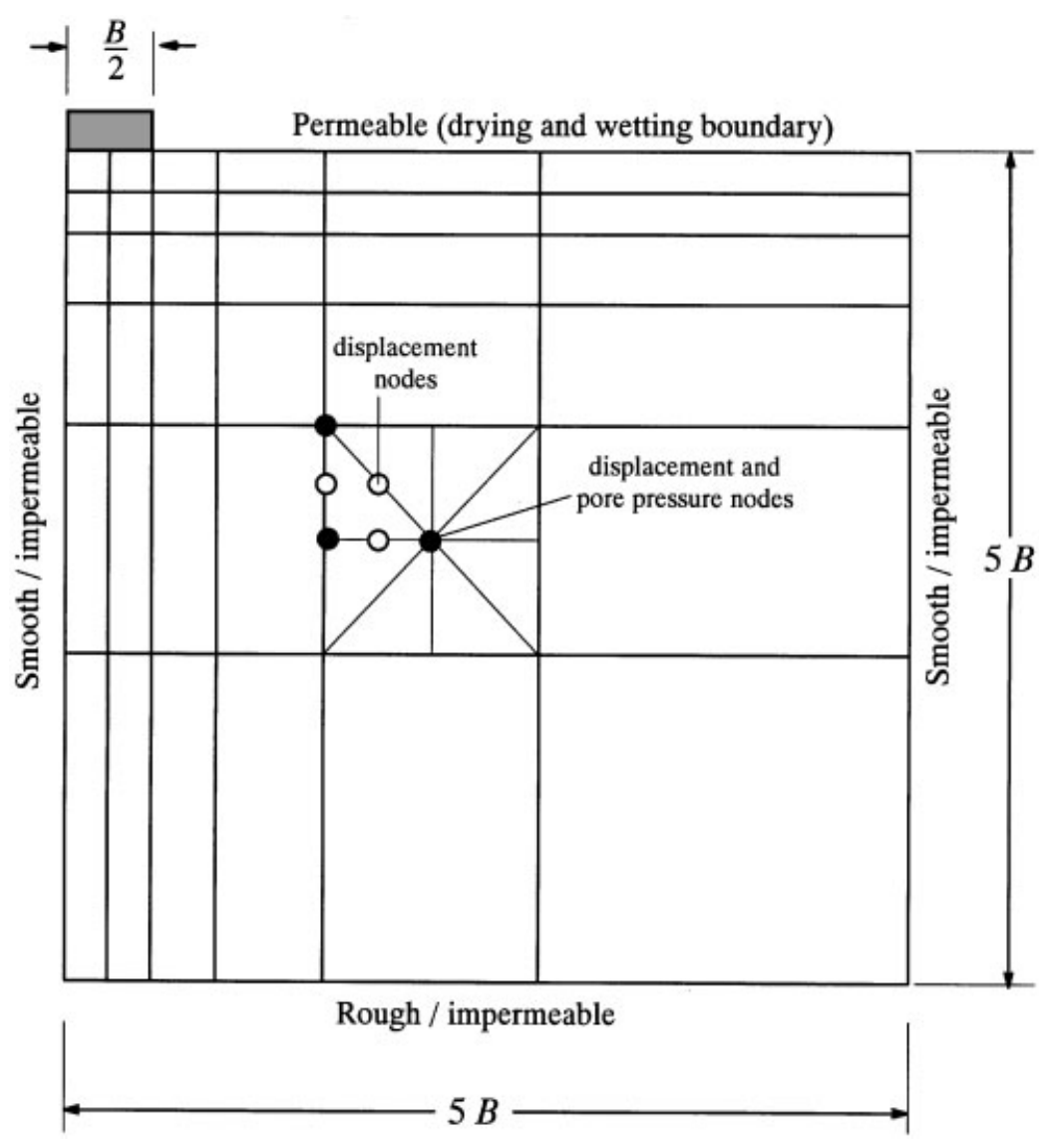

Figure 6. Footing mesh (625 nodes, 288 elements). 
The MCC model is again used to simulate the soil response, but the slope of the critical state line, $M$, is now assumed to vary with the Lode angle in the deviatoric plane in accordance with a rounded Mohr-Coulomb failure surface [7]. The material properties used in the analysis are as follows:

$$
\begin{aligned}
& M=0.984, \quad \mu=0.3, \quad \lambda_{0}=0.2, \quad x=0.02, \quad N=2.8, \quad r=0.9, \quad \beta=0.012\left(\mathrm{kPa}^{-1}\right) \\
& a=10(\mathrm{kPa}), \quad b=0.5, \quad c=1.0, \quad m=2.0, \quad k_{\mathrm{s}}=10^{-6}\left(\mathrm{~m} \mathrm{~s}^{-1}\right) \\
& \left.\gamma=16(\mathrm{kN} \mathrm{m})^{-3}\right), \quad K_{0}=0.72
\end{aligned}
$$

where $M$ is the slope of the CSL at triaxial compression stress state, $\gamma$ is the unit weight and $K_{0}$ is the ratio of the horizontal and vertical stresses in situ. The last two parameters are used to generate the in situ stresses before the footing is displaced, and the constitutive stress parameter is set to $\varphi=\sqrt{S_{\mathrm{r}}}$.

For all analyses, the initial stresses in the soil layer are generated using the body loads which correspond to the total soil unit weight. During this stage, we assume that the material is nonlinear elastic and fully saturated, with the water table at the ground surface. Once the hydrostatic initial stresses are established, the initial yield surface locations for the fully saturated condition are determined so that the overconsolidation pressure at the ground surface is $100 \mathrm{kPa}$. The nodal displacements are also initialized to zero at this time. A uniform suction is then applied to the nodes on the top boundary in 100 equal coarse increments over a time period of $10^{8}$ time units (s). The suction values considered here are 0,10 and $100 \mathrm{kPa}$, with the first value corresponding to a fully saturated condition. After the drying phase, the footing is loaded to a total displacement of $0.15 B$. This displacement is applied in 100 equal coarse increments over a time period of $10^{8} \mathrm{~s}$, so that the rate of loading is slow enough to ensure fully drained conditions. The total iterations and CPU times given in the following tables exclude those used during establishment of the initial stress field.

In the analyses, the yield surface tolerance YTOL is set to $10^{-9}$, the stress error tolerance STOL to $10^{-6}$, and the Newton-Raphson iteration tolerance ITOL to $10^{-5}$. The displacement error tolerance DTOL, which controls the time integration accuracy, is set to $10^{-3}$. This set of values are typical of those used in practical analyses, though changing them by one or two orders of magnitude does not usually affect the results significantly.

The predicted load-displacement curves for the three different surface suction values are shown in Figure 7. For the zero suction case, which corresponds to a fully saturated soil, the predicted footing load increases rapidly to around $85 \mathrm{kPa}$ at a displacement of $0.12 \mathrm{~B}$, gently increases to about $100 \mathrm{kPa}$ at a displacement of around $0.26 \mathrm{~B}$, and then finally starts to decrease at large displacements. When the surface is subject to a suction of $10 \mathrm{kPa}$, the predicted footing load is larger than that for the fully saturated case, and does not asymptote towards a limiting value within the applied displacement. The predicted footing load for the surface suction of $100 \mathrm{kPa}$ is the largest, and does not approach a collapse load either. The predicted settlements during the drying phase are shown in Figure 8. Drying to a suction of $10 \mathrm{kPa}$ at the ground surface causes a settlement of $0.021 \mathrm{~m}$, while drying to a suction of $100 \mathrm{kPa}$ gives a settlement of $0.057 \mathrm{~m}$. In the latter case, $10 \%$ of the total applied suction (or a time period of $10^{7} \mathrm{~s}$ ) also gives a settlement of $0.021 \mathrm{~m}$, which indicates the difference due to the drying rates $\left(10^{-6} \mathrm{vs}\right.$ $10^{-7} \mathrm{kPa} \mathrm{s}^{-1}$ ) is negligible. The results shown in Figures 7 and 8 are intuitively reasonable and match the observation that the soil becomes stiffer as it dries. 


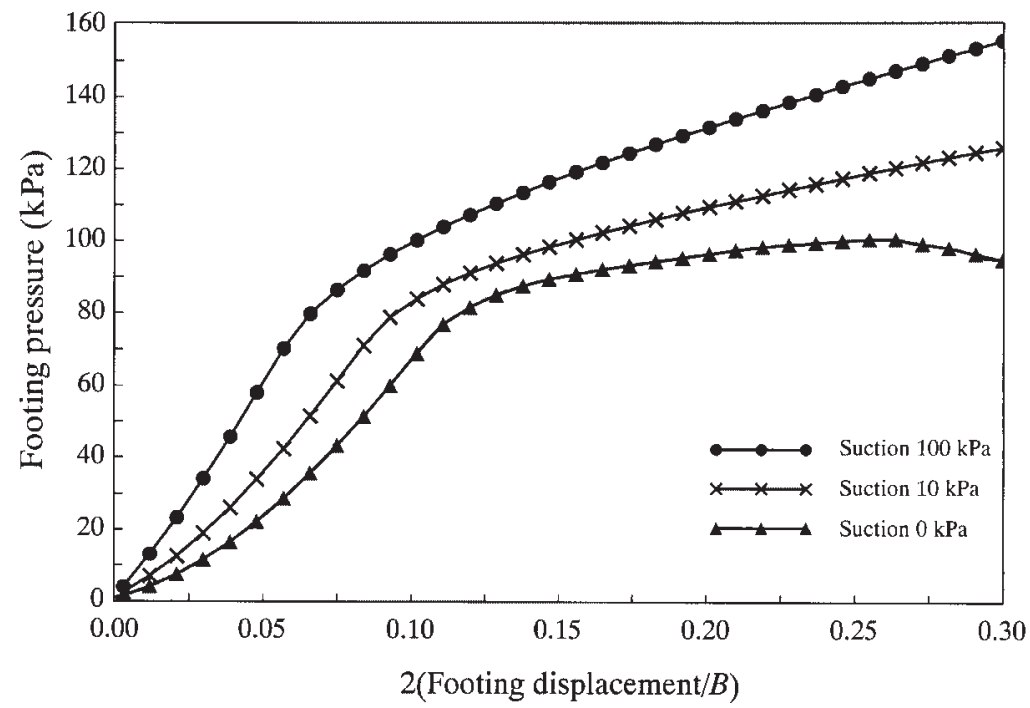

Figure 7. Load-displacement response of rigid footing with different surface suctions (100 coarse time steps).

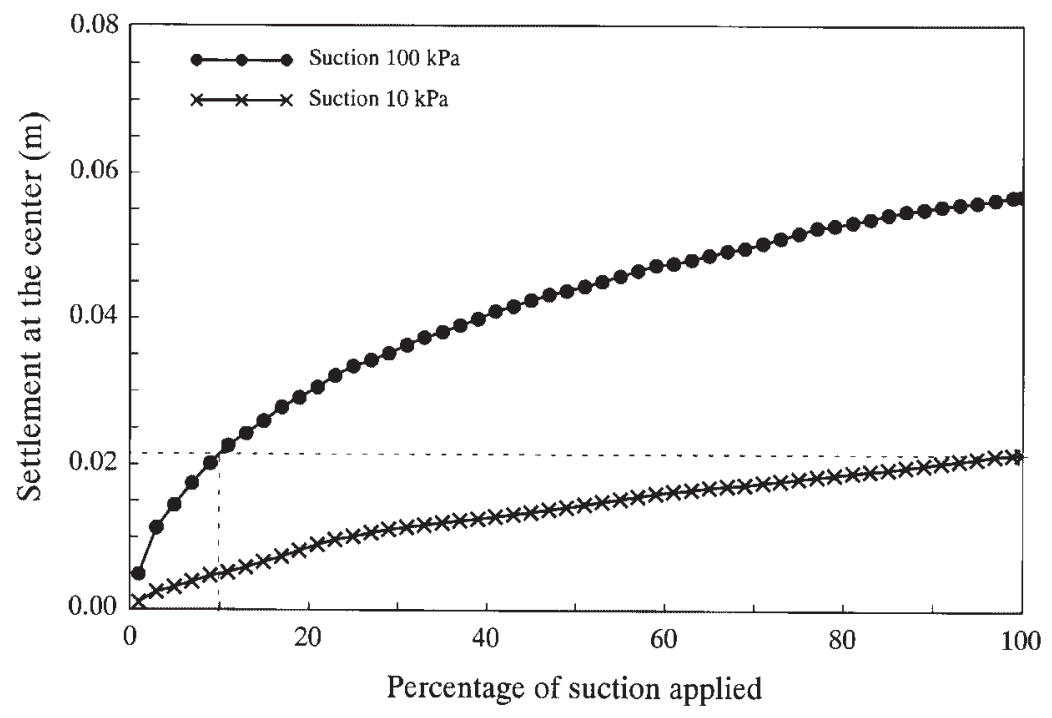

Figure 8. Settlement due to drying (100 coarse time steps).

The numerical statistics for this example are summarized in Table II. Each analysis is repeated for two sets of tolerances and two sets of coarse time steps and the CPU times, the total number of time substeps and the maximum strain subincrements per time substep are given separately for the drying and loading phases. Note the drying phase generally requires more 
Table II. Numerical statistics for the rigid footing problem.

\begin{tabular}{|c|c|c|c|c|c|c|c|c|}
\hline \multirow[t]{2}{*}{$\begin{array}{l}\text { Suction } \\
(\mathrm{kPa})\end{array}$} & \multirow[t]{2}{*}{$\begin{array}{l}\text { Number of } \\
\text { increments }\end{array}$} & \multicolumn{2}{|c|}{ CPU time (s) } & \multicolumn{2}{|c|}{ Total time substeps } & \multicolumn{2}{|c|}{$\begin{array}{l}\text { Max strain substeps } \\
\text { per time substep }\end{array}$} & \multirow[t]{2}{*}{$\begin{array}{c}\text { Final footing } \\
\text { pressure }(\mathrm{kPa})\end{array}$} \\
\hline & & Drying & Loading & Drying & Loading & Drying & Loading & \\
\hline \multirow{3}{*}{0} & & $(\mathrm{DTOL}=$ & $=10^{-3}$, IT & $\mathrm{L}=10^{-}$ & $\mathrm{STOL}=$ & -6 , YTOI & $\left.=10^{-9}\right)$ & \\
\hline & 100 & - & 421 & - & 362 & - & 997 & 94.358 \\
\hline & 200 & - & 419 & - & 407 & 一 & 972 & 94.335 \\
\hline \multirow[t]{2}{*}{10} & 100 & 1354 & 318 & 1566 & 330 & 1 & 663 & 125.535 \\
\hline & 200 & 1388 & 312 & 1640 & 382 & 1 & 330 & 125.533 \\
\hline \multirow[t]{2}{*}{100} & 100 & 2225 & 167 & 2419 & 137 & 1 & 876 & 155.127 \\
\hline & 200 & 2136 & 201 & 2347 & 226 & 1 & 681 & 155.124 \\
\hline \multirow{3}{*}{0} & & $(\mathrm{DTOL}=$ & $=10^{-2}$, IT & $\mathrm{L}=10^{-}$ & $\mathrm{STOL}=$ & ${ }^{-6}$, YTOI & $\left.10^{-9}\right)$ & \\
\hline & 100 & - & 349 & - & 242 & - & 1000 & 94.156 \\
\hline & 200 & 一 & 356 & 一 & 251 & 一 & 1000 & 94.122 \\
\hline \multirow[t]{2}{*}{10} & 100 & 738 & 264 & 985 & 333 & 1 & 880 & 125.529 \\
\hline & 200 & 756 & 255 & 1066 & 366 & 1 & 782 & 125.529 \\
\hline \multirow[t]{2}{*}{100} & 100 & 903 & 95 & 1059 & 104 & 1 & 675 & 155.177 \\
\hline & 200 & 896 & 158 & 1090 & 204 & 1 & 716 & 155.077 \\
\hline
\end{tabular}

time substeps and more CPU time than the loading phase, even though no strain subincrementation is required because the deformation is non-linear elastic and can be integrated analytically. As the suction applied at the ground surface increases, the maximum number of strain subincrements used during the loading phase decreases. For the fully saturated case, the maximum number of strain subincrements are equal or close to the limit set in the algorithm. These results suggest that, for unsaturated soils, it is more difficult to control the global time integration error than it is to control the local stress integration error.

The CPU time in Table II does not vary significantly with the size of the initial coarse time steps. Indeed, for the highly saturated cases, the CPU time for the drying phase and the loading phase is largely independent of this quantity. In the $100 \mathrm{kPa}$ suction examples, the sum of the CPU times for the drying and loading phases varies by less than $5 \%$ when the number of coarse time steps increases from 100 to 200 . For the loading phase alone, the CPU time for the runs with 100 coarse time steps are $20-40 \%$ less than that for the runs with 200 coarse time steps.

As the number of coarse time steps is doubled from 100 to 200, the total number of time substeps increases by less than $15 \%$ for the cases of 0 and $10 \mathrm{kPa}$ suction, and by about $65 \%$ for the case of $100 \mathrm{kPa}$ suction. As expected, the maximum number of strain subincrements per time substep decreases as the number of coarse time steps increases. This decrease, which reflects the smaller incremental strains that are generated by the algorithm, offsets the effect of the increase in the number of time substeps and explains why the total CPU time is not significantly influenced by using smaller coarse time steps.

The predicted final footing pressure at the end of the analyses may be used as a rough measure of the accuracy of the solution. These values, given in Table II, are largely unaffected by the 
number of coarse time steps, the displacement error tolerance, or the iteration tolerance. Indeed, the maximum discrepancy caused by the use of different coarse time steps is less than $0.07 \%$, and arises for the runs with $100 \mathrm{kPa}$ suction, DTOL $=10^{-2}, \mathrm{ITOL}=10^{-4}, \mathrm{STOL}=10^{-6}$ and YTOL $=10^{-9}$. The effect of using different tolerances is less than $0.3 \%$, and occurs for the fully saturated case.

The influence of the displacement and iteration tolerances on the number of time substeps, maximum number of strain subincrements, and CPU times are also shown in Table II. In general, increasing the tolerances DTOL and ITOL by an order of magnitude results in fewer time substeps, more strain subincrements, and lower CPU times. For the $10 \mathrm{kPa}$ suction cases, the number of time substeps used in the drying phase is reduced roughly by one-third, and the corresponding CPU time is reduced by one-half. In the drying phase of the $100 \mathrm{kPa}$ suction case, the number of time substeps and CPU time are reduced roughly by one half.

In summary, the results for this problem indicate that the efficiency and accuracy of the numerical algorithms presented in Part I are not significantly influenced by the choice of the initial time steps. As expected, the error control tolerances affect their efficiency. Compared with fully saturated soils, unsaturated soils require a similar amount of work to integrate the stressstrain relations, but more work to integrate the global equations.

Drying, loading and wetting of flexible footing on soil that expands upon wetting. This example again considers the strip footing problem shown in Figure 6, but imposes different boundary conditions in three distinct phases. In the first two phases, the ground surface is dried by a $100 \mathrm{kPa}$ suction and then the footing is vertically loaded to $100 \mathrm{kPa}$. In the final phase, the surface soil adjacent to the footing is wetted to zero suction. All these boundary conditions are imposed at a rate which is slow enough to maintain fully drained conditions. This problem involves a complex loading path and simulates the seasonal drying and wetting that actual footings on unsaturated soils are subjected to. As the footing is loaded by a uniform vertical pressure, and not by uniform imposed vertical displacements, it is taken to be perfectly flexible.

The constitutive models and the material parameters used in this example are identical to those in the previous footing example, so that we expect volume expansion upon wetting. The initial stresses are generated again using the body loads which correspond to the total soil unit weight, and the initial yield surface locations are set as before. After the initial conditions are established, the yield surface locations for the fully saturated condition are again adjusted so that the overconsolidation pressure at the ground surface is $100 \mathrm{kPa}$ and increases linearly with depth. The uniform suction of $100 \mathrm{kPa}$ is applied to the nodes on the top boundary in 100 equal coarse increments over a period of $10^{8}$ time units (s). After this drying phase, the footing is loaded to a pressure of $100 \mathrm{kPa}$ in increments of $1 \mathrm{kPa}$ over a further period of $10^{8} \mathrm{~s}$. Once the footing is fully loaded, the ground surface outside the footing is wetted until the pore pressure is $0 \mathrm{kPa}$, while the pore pressures at the nodes under the footing are unrestrained with a no-flow boundary condition. The wetting phase is also carried out in 100 equal coarse time steps within a total time of $10^{8} \mathrm{~s}$.

The predicted displacements at different positions on the ground surface at various times are shown in Figure 9. During the drying phase, the ground surface settles uniformly by $5.7 \mathrm{~cm}$. Since the footing is flexible, loading it causes differential movement with a settlement of $12.7 \mathrm{~cm}$ at its centre $(x=0), 7.2 \mathrm{~cm}$ at its edge $(x=0.5 B)$, and almost zero at $5 B$ away from its centre $(x=5 B)$. During the wetting phase, differential heave along the ground surface is predicted, with a heave of $1.8 \mathrm{~cm}$ at the centre of the footing, $2 \mathrm{~cm}$ at the edge of the footing, and $4.7 \mathrm{~cm}$ at $5 B$ 


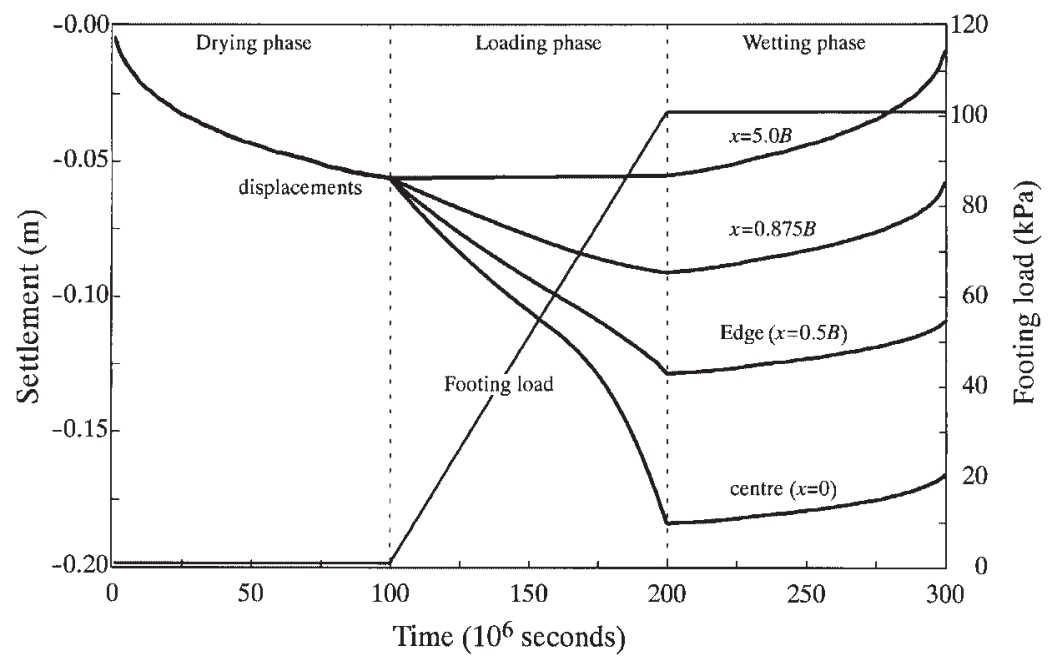

Figure 9. Predicted settlements at the ground surface (100 coarse time steps in each phase, $\mathrm{DTOL}=10^{-3}, \mathrm{ITOL}=10^{-5}$.

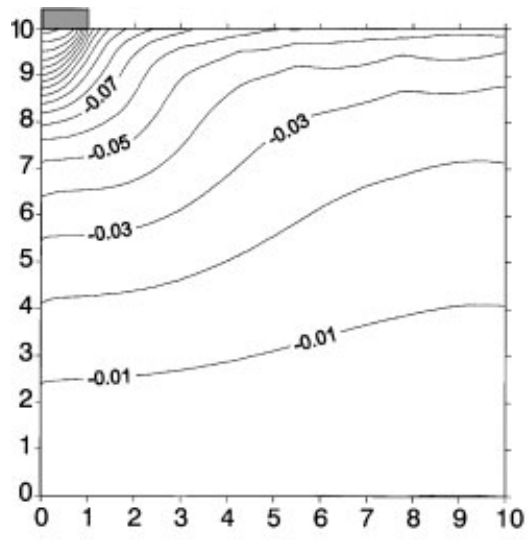

(a) Vertical displacements at end of loading phase

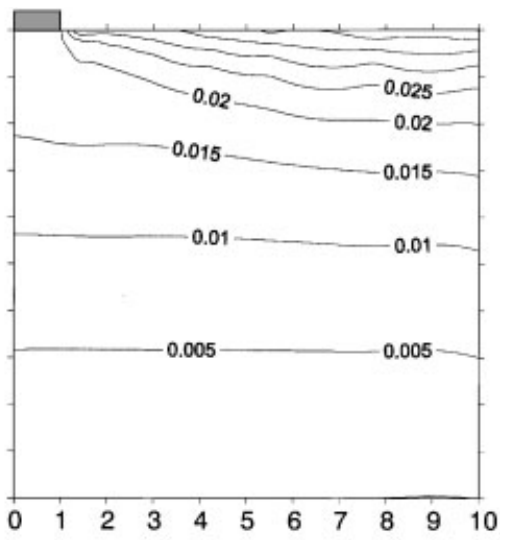

(b) Vertical displacements caused by wetting

Figure 10. Displacement contours (100 coarse time steps in each phase, DTOL $=10^{-3}$, ITOL $=10^{-5}$ ): (a) Vertical displacements at end of loading phase; (b) Vertical displacements caused by wetting.

away from the centre of the footing. The sum of the computed reaction forces at the footing nodes are also shown in Figure 9. This force is close to zero during the drying phase, equals the applied external forces during loading phase, and then remains constant during the wetting phase.

Figures 10(a) and 10(b) show, respectively, contour plots of the total vertical displacements at the end of the loading phase and the incremental vertical displacements caused by the wetting phase. Note that the half-width of the footing $B / 2$ was set to $1 \mathrm{~m}$ in the analysis so that the 
domain shown in Figure 6 covers an area of $10 \times 10 \mathrm{~m}^{2}$. In Figure 10(a), the displacements are all negative (indicating settlement) and the maximum movement occurs at the centre of the footing. At a distance of $5 B$ away from the centre, the displacement at the ground surface is about $-5.6 \mathrm{~cm}$, which is close to the settlement predicted during the drying phase. In Figure 10(b), the incremental displacements are all positive (indicating heave) and the maximum movement occurs at the ground surface at a distance of $5 B$ away from the centre of the footing. The heave underneath the footing varies between 1.5 and $2 \mathrm{~cm}$.

Total pore water pressure contours at the end of the loading and wetting phases are plotted in Figures 11(a) and 11(b), respectively. In Figure 11(a), the pore pressure contours are close to horizontal, which confirms that the footing loading does not change the total pore pressure distribution under fully drained conditions. The zero pore pressure line, which indicates the water table level, is about $1.3 \mathrm{~m}$ below the ground surface. This implies that the $100 \mathrm{kPa}$ suction imposed at the ground surface has caused the water table to drop by $1.3 \mathrm{~m}$. In Figure 11(b), the water table at the end of the wetting phase has risen back to the ground surface at all points just outside the footing. Some suction, however, still exists beneath the footing, which implies that further heave may occur if the boundary conditions are kept unchanged. About $2 \mathrm{~m}$ below the ground surface, steady-state conditions have been reached with the pore pressure contours being approximately horizontal.

The results presented above were obtained using a yield surface tolerance of YTOL $=10^{-9}$, a stress error tolerance of STOL $=10^{-6}$, a Newton-Raphson iteration tolerance of ITOL $=10^{-5}$ and a displacement error tolerance of DTOL $=10^{-3}$.

Numerical statistics for various flexible footing analyses are summarized in Table III. The overall CPU time does not vary significantly with the number of coarse time steps used, though the CPU time used in the loading phase with 100 coarse time steps is $30-40 \%$ less than the corresponding CPU time with 200 coarse time steps. This is a direct result of the fact that the

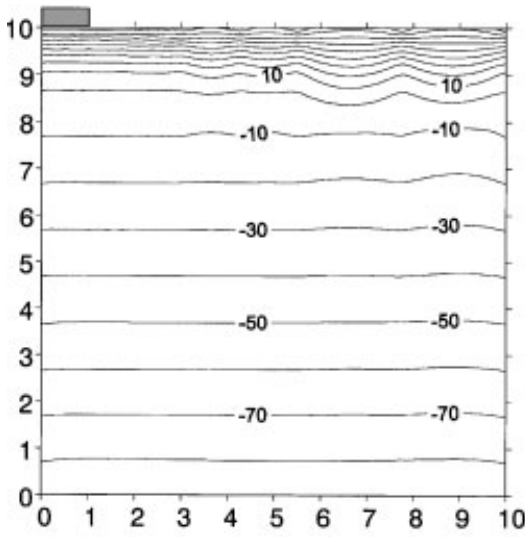

(a) Pore water pressure at end of loading phase

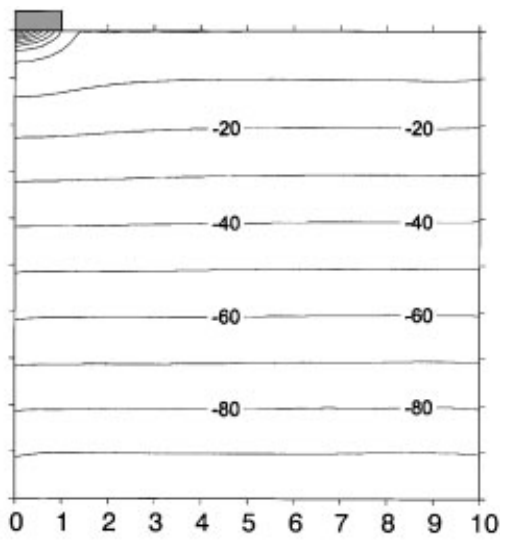

(b) Pore water pressures at end of wetting phase

Figure 11. Pore water pressure contours (100 coarse time steps in each phase, DTOL $=10^{-3}$, ITOL $=10^{-5}$ ): (a) Pore water pressure at end of loading phase; (b) Pore water pressures at end of wetting phase. 
Table III. Numerical statistics for the flexible footing problem.

\begin{tabular}{|c|c|c|c|c|c|c|c|c|c|c|c|}
\hline \multirow[t]{2}{*}{ Tolerances } & \multirow[t]{2}{*}{$\begin{array}{l}\text { Number of } \\
\text { time steps }\end{array}$} & \multicolumn{3}{|c|}{ CPU time (s) } & \multicolumn{3}{|c|}{$\begin{array}{l}\text { Total time } \\
\text { substeps }\end{array}$} & \multicolumn{3}{|c|}{$\begin{array}{l}\text { Max strain substeps } \\
\text { per time substep }\end{array}$} & \multirow[t]{2}{*}{$\begin{array}{c}\text { Final central } \\
\text { displacement }(\mathrm{m})\end{array}$} \\
\hline & & Dry & Load & Wet & Dry & Load & Wet & Dry & Load & Wet & \\
\hline $\begin{array}{l}\text { DTOL }=10^{-3} \\
\text { ITOL }=10^{-5}\end{array}$ & $\begin{array}{l}100 \\
200\end{array}$ & $\begin{array}{l}2225 \\
2136\end{array}$ & $\begin{array}{l}102 \\
148\end{array}$ & $\begin{array}{l}757 \\
819\end{array}$ & $\begin{array}{l}2047 \\
2045\end{array}$ & $\begin{array}{l}108 \\
203\end{array}$ & $\begin{array}{l}682 \\
770\end{array}$ & $\begin{array}{l}1 \\
1\end{array}$ & $\begin{array}{l}81 \\
44\end{array}$ & $\begin{array}{l}181 \\
157\end{array}$ & \\
\hline $\begin{array}{l}\text { DTOL }=10^{-2} \\
\text { ITOL }=10^{-4}\end{array}$ & $\begin{array}{l}100 \\
200\end{array}$ & $\begin{array}{l}903 \\
896\end{array}$ & $\begin{array}{c}78 \\
134\end{array}$ & $\begin{array}{l}272 \\
247\end{array}$ & $\begin{array}{l}872 \\
917\end{array}$ & $\begin{array}{l}110 \\
203\end{array}$ & $\begin{array}{l}328 \\
350\end{array}$ & $\begin{array}{l}1 \\
1\end{array}$ & $\begin{array}{l}427 \\
694\end{array}$ & $\begin{array}{l}190 \\
209\end{array}$ & $\begin{array}{l}-0.1661 \\
-0.1662\end{array}$ \\
\hline
\end{tabular}

number of time substeps used in the drying and wetting phases is largely independent of the coarse time-step regime, and indicates that substepping takes place only when needed. Unlike the previous example of a rigid footing, the loading phase does not require much substepping and thus the total time substeps are close to the numbers of coarse steps.

The maximum number of strain subincrements per time substep are also given in Table III. The drying phase involves only elastic deformation and thus no strain subincrementation is required. Compared to the previous rigid footing example, which is loaded by prescribed displacements, the loading phase of the flexible footing uses less strain subincrements. The data in Table III indicate that the wetting phase also involves plastic deformation. As expected, the final displacement at the centre of the footing is not affected by the number of coarse time steps.

Increasing the displacement and iteration tolerances results in fewer time substeps, lower CPU times, but more strain subincrements. Raising DTOL and ITOL by an order of magnitude reduces the number of time substeps used in the drying and wetting phases by roughly one-half, and at the same time reduces the CPU time by about $60 \%$. Interestingly, the number of time substeps and the CPU time for the loading phase are less sensitive to these tolerances. The changes in the displacement and iteration tolerances do not affect the predicted final central displacements, which suggests that the higher values are sufficiently accurate.

In general, the results from this problem again confirm that the efficiency and accuracy of the numerical algorithms presented in Part I are not significantly influenced by the initial number of coarse time steps.

Drying, loading and wetting of flexible footing on soil that collapses upon wetting. The previous example considered a soil with an initial stress on the yield surface which expands upon wetting. In this example, we simulate a soil that shrinks (collapses) upon wetting. The problem is identical to the previous one, except that the material parameters for the MCC model are as follows:

$$
\begin{aligned}
& M=0.984, \quad \mu=0.3, \quad \lambda_{0}=0.2, \quad x=0.02, \quad N=2.8, \quad r=0.7, \quad \beta=0.012\left(\mathrm{kPa}^{-1}\right) \\
& a=10(\mathrm{kPa}), \quad b=0.5, \quad c=1.0, \quad m=2.0, \quad k_{\mathrm{s}}=10^{-6}\left(\mathrm{~m} \mathrm{~s}^{-1}\right) \\
& \left.\gamma=16(\mathrm{kN} \mathrm{m})^{-3}\right), \quad K_{0}=0.72
\end{aligned}
$$

Note that the parameter $r$ is changed from 0.9 to 0.7 , and the constitutive stress parameter is set to $\varphi=S_{\mathrm{r}}$ instead of $\varphi=\sqrt{S_{\mathrm{r}}}$. Such a combination ensures that the yield surface size increases faster than the constitutive stress as the suction increases. 
The initial stresses and yield surface locations are set in the same way as in the previous example. After the initial conditions are established, the yield surface locations for the fully saturated condition are adjusted so that the overconsolidation pressure at the ground surface is $50 \mathrm{kPa}$ and increases linearly with depth. A uniform suction of $100 \mathrm{kPa}$ is then applied to the pore pressure nodes on the top boundary in 100 equal coarse increments over a time period of $10^{8}$ time units (s). After this drying phase, the footing is loaded to a pressure of $100 \mathrm{kPa}$ using $1 \mathrm{kPa}$ increments over $10^{8} \mathrm{~s}$. Once the footing is fully loaded, the ground surface adjacent to it is wetted to zero pore pressure in steps of $1 \mathrm{kPa}$, while the pore pressures at the nodes under the footing are unrestrained with a no-flow boundary condition. This wetting phase also takes place over a total time period of $10^{8} \mathrm{~s}$.

The predicted displacements at different positions on the ground surface are shown in Figure 12. In the drying phase, the ground surface settles uniformly by $5.0 \mathrm{~cm}$. As expected, the footing settlement is non-uniform, with a movement of $29.2 \mathrm{~cm}$ at its centre and $18.6 \mathrm{~cm}$ at its edge. At a distance of $5 B$ from the footing centre, there is a surface heave of $0.3 \mathrm{~cm}$. During wetting, the ground surface rises or continues to settle, depending on the location. At the centre of the footing, where plastic deformation has occurred during the loading phase, a further settlement of $4.3 \mathrm{~cm}$ is predicted. At the edge of the footing, the ground surface also settles a further $2.4 \mathrm{~cm}$. However, at distances of $0.875 \mathrm{~B}$ and $5 \mathrm{~B}$ away from the footing centre, the ground surface rises about 5.7 and $3.4 \mathrm{~cm}$, respectively. These different responses arise because of the stress states prior to wetting. For soil elements underneath the footing, the loading causes plastic yielding and the stress states are therefore on the yield surface. Wetting under this stress condition causes plastic yielding, and the soil elements undergo a decrease in volumetric strain. Indeed, this process is similar to the stress path from points $C$ to D in Figures 5(c) and 5(d) in the triaxial test example. However, for soil elements far away from the footing, the stress states are within the yield surface and the soil is overconsolidated (due to drying). Wetting under these

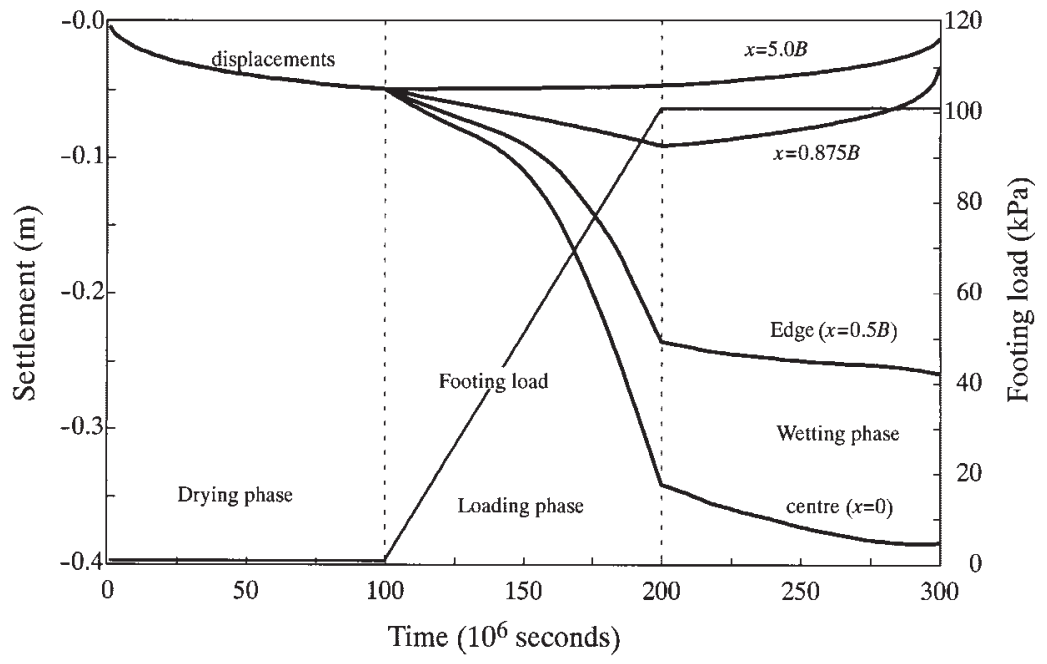

Figure 12. Predicted settlements at the ground surface (100 coarse time steps in each phase,

$$
\text { DTOL } \left.=10^{-3} \text {, ITOL }=10^{-4}\right) \text {. }
$$


conditions creates stress paths similar to that from point B to A in Figures 5(c) and 5(d), i.e. elastic unloading, and the soil volume increases.

Figures 13(a) and 13(b) show, respectively, contours of the vertical displacements at the end of the loading phase and the incremental vertical displacements generated by the wetting phase. In the former figure, displacements are all negative (indicating settlement) and the maximum deformation occurs at the centre of the footing. At a distance of $5 B$ away from the centre, the displacement at the ground surface remains at $-5.0 \mathrm{~cm}$, which is equal to the settlement at the end of the drying phase. This indicates that the footing load has not caused any vertical displacement at a distance of $5 B$ (or greater) away from the centre. In Figure 13(b), the incremental vertical displacements caused by wetting vary from $5.7 \mathrm{~cm}$ of heave to $-5.0 \mathrm{~cm}$ of settlement. The maximum settlement occurs just underneath the footing to a distance of $0.375 B$ from the centre, while the maximum heave occurs at the ground surface at $0.875 B$ from the centre. Just underneath the edge of the footing, the vertical displacement changes rapidly from settlement to heave. The pore pressure contours at the end of the loading and wetting phases, shown in Figures 14(a) and 14(b), respectively, are similar to those for the expansive-wetting case shown in Figure 11. At the end of wetting phase the pore pressure distribution is close to hydrostatic, except underneath the footing where some suction again exists.

The results presented above were obtained using a yield surface tolerance of YTOL $=10^{-9}$, a stress error tolerance of STOL $=10^{-6}$, a Newton-Raphson iteration tolerance of ITOL $=10^{-4}$, and a displacement error tolerance of DTOL $=10^{-3}$.

Numerical statistics for this example are summarized in Table IV, where the same problem is analysed using different coarse time steps and different stress and yield surface tolerances. As before, the total CPU time does not vary significantly with the number of coarse time steps, particularly for the drying and wetting phases. However, in the loading phase, the CPU time for 100 coarse time steps is $30-40 \%$ less than the CPU time for 200 coarse time steps. The total number of time substeps is insensitive to the number of coarse time steps, which suggests that

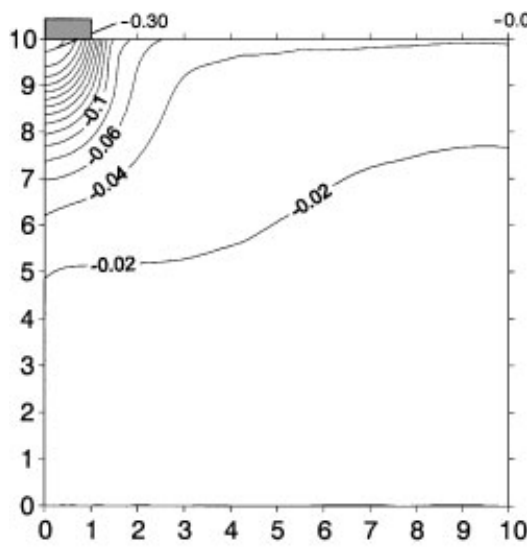

(a) Vertical displacements at the end of loading phase

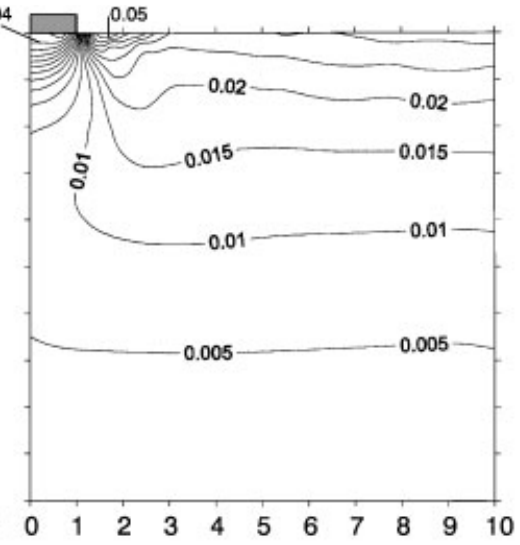

(b) Vertical displacements caused by wetting

Figure 13. Displacement contours (100 coarse time steps in each phase, DTOL $=10^{-3}$, ITOL $\left.=10^{-4}\right)$ : $(\mathrm{a})$ Vertical displacements at end of loading phase; (b) Vertical displacements caused by wetting. 


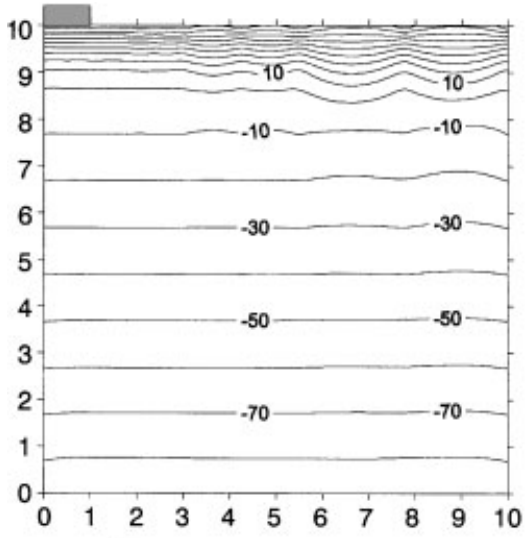

(a) Pore water pressure at end of loading phase

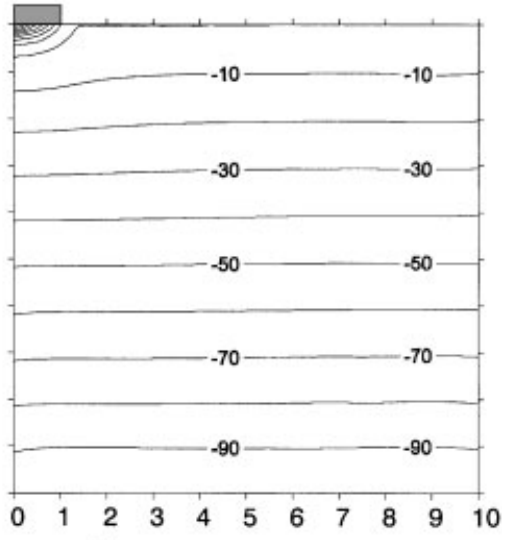

(b) Pore water pressures at end of wetting phase

Figure 14. Pore water pressure contours (100 coarse time steps in each phase, DTOL $=10^{-3}$, ITOL $=10^{-4}$ ): (a) Pore water pressure at end of loading phase; (b) Pore water pressures at end of wetting phase.

Table IV. Numerical statistics for flexible footing problem

\begin{tabular}{|c|c|c|c|c|c|c|c|c|c|c|c|}
\hline \multirow[t]{2}{*}{ Tolerances } & \multirow[t]{2}{*}{$\begin{array}{l}\text { Number of } \\
\text { time steps }\end{array}$} & \multicolumn{3}{|c|}{ CPU time (s) } & \multicolumn{3}{|c|}{$\begin{array}{l}\text { Total time } \\
\text { substeps }\end{array}$} & \multicolumn{3}{|c|}{$\begin{array}{l}\text { Max strain substeps } \\
\text { per time substep }\end{array}$} & \multirow[t]{2}{*}{$\begin{array}{c}\text { Final central } \\
\text { displacement }(\mathrm{m})\end{array}$} \\
\hline & & Dry & Load & Wet & Dry & Load & Wet & Dry & Load & Wet & \\
\hline STOL & 100 & 969 & 108 & 489 & 1180 & 1301 & 1814 & 1 & 24 & 201 & \\
\hline $\mathrm{YTOL}=10^{-9}$ & 200 & 998 & 154 & 453 & 1258 & 1472 & 2003 & 1 & 295 & 178 & -0.3846 \\
\hline $\mathrm{STOL}=10^{-5}$ & 10 & 963 & 93 & 463 & & & & 1 & r & 1 & \\
\hline $\mathrm{YTOL}=10^{-8}$ & 200 & 985 & 140 & 456 & 1236 & 1450 & 2001 & 1 & 79 & 97 & -0.3846 \\
\hline
\end{tabular}

substepping takes place only when needed. The maximum number of strain subincrements per time substep does change as the number of coarse time steps changes, but not in a consistent way. The predicted final displacements at the centre of the footing are not affected by the number of coarse time steps.

The results in Table IV also show that increasing the stress error and yield surface tolerances by one order of magnitude does not strongly affect the number of time substeps or CPU time, but does reduce the maximum number of strain subincrements. Theoretically, increasing STOL by an order of magnitude from $10^{-6}$ to $10^{-5}$ should reduce the maximum number of strain subincrements by a factor of approximately $\sqrt{10}$. In practice, the maximum number of strain subincrements used in the drying and wetting phases is reduced by a factor which is between two and three. The final central displacements are unaffected by the changes made to the tolerances. This suggests that the latter are sufficiently stringent for practical purposes.

Drying, undrained loading and fast wetting of flexible footing on soil that expands upon wetting. In this example, the strip footing problem shown in Figure 6 is subjected to fast loading and fast 
wetting. First, the soil at the ground surface is dried slowly to a suction of $100 \mathrm{kPa}$ over a period of $10^{8}$ time units. After that, the soil under the footing is vertically loaded to $50 \mathrm{kPa}$ in $10^{5}$ time units, and the soil outside the footing is wetted to zero suction over a further period of $10^{5}$ time units, with the ground surface under the footing not being allowed to drain. The wetting phase is relatively short, representing the case of rain wetting the ground surface. Finally, the boundary conditions are kept fixed and the displacements and pore pressures are computed at the end of a time period of $10^{6}$ units. This last time interval is referred to as the expansion phase. In total, this example involves four phases: drying, loading, wetting and expansion. The constitutive model and material parameters used for this case are identical to those used for the rigid footing example.

The predicted surface displacements at various distances from the footing centre are shown in Figure 15. In the drying phase, the ground surface settles uniformly by $5.7 \mathrm{~cm}$. As before, the footing load causes differential deformations, with a settlements of 4.6 and $3.4 \mathrm{~cm}$ at the centre and edge of the footing. A surface heave of $0.4 \mathrm{~cm}$ occurs at a distance of $5 B$ away from the centre. During the wetting phase, very little surface movement near the footing is predicted, while a heave of $0.7 \mathrm{~cm}$ occurs at $5 B$ away from the centre. When the wetting is completed, the pore water pressures at the ground surface are kept at zero suction. It is then observed that the ground surface heaves about $2.1 \mathrm{~cm}$ under the centre of the footing, $2.3 \mathrm{~cm}$ at the edge of the footing, and $5.3 \mathrm{~cm}$ at $5 B$ away from the centre of the footing. Most of this heave take place within a time period of $0.5 \times 10^{6}$ after the wetting phase. Note that the time scale in each phase in Figure 15 is different.

The results presented above were obtained using a yield surface tolerance of YTOL $=10^{-9}$, a stress error tolerance of STOL $=10^{-6}$, a Newton-Raphson iteration tolerance of ITOL $=10^{-5}$ and a displacement error tolerance of DTOL $=10^{-3}$. Different error tolerances were again used to study the numerical performance of the finite-element algorithms and the results are

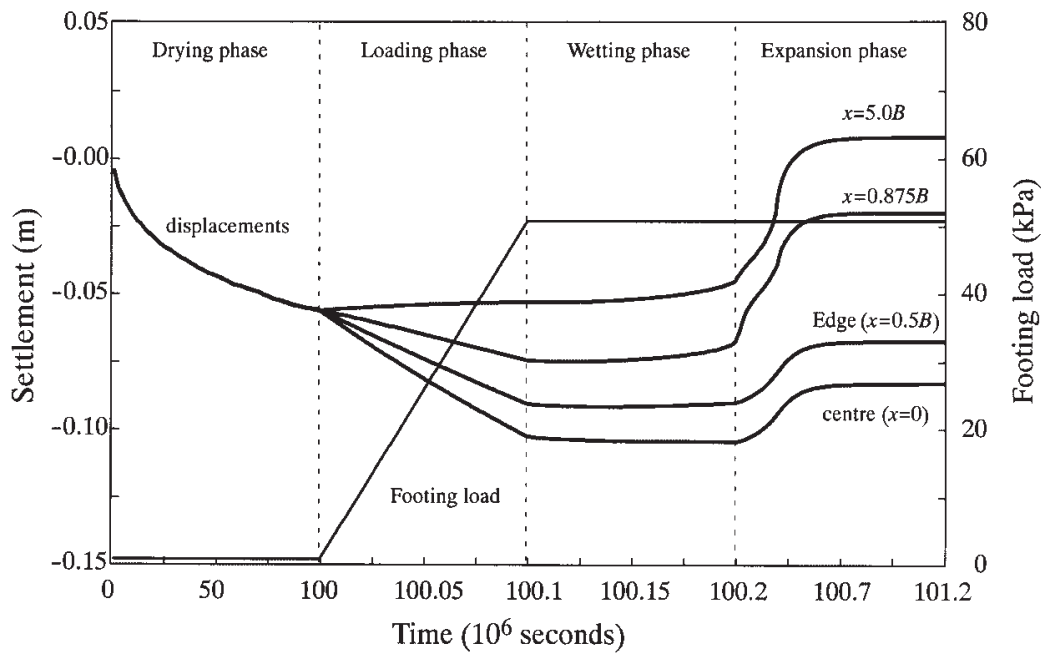

Figure 15. Predicted settlements at the ground surface (Note each phase has a different time scale, 100 coarse time steps in each phase, DTOL $=10^{-3}$, ITOL $=10^{-5}$ ). 
summarized in Table V. As expected, the CPU times increase as DTOL and ITOL decrease, with the latter having a marked effect. This reflects the fact that the number of time substeps also increases for the drying and expansion phases as DTOL and ITOL decrease. The loading phase and wetting phase do not require any time substepping, except for DTOL $=10^{-4}$ and $\mathrm{ITOL}=$ $10^{-6}$. The maximum number of strain subincrements per time substep is more or less constant, except for the case with DTOL $=10^{-4}$ and ITOL $=10^{-6}$, and no subincrementation is required for the drying and loading phases where the deformation is purely elastic. For this case, the predicted final displacement at the centre of the footing is not affected by selected variations in the tolerances DTOL and ITOL.

The results from this problem confirm that small variations in the user-defined error tolerances may affect the efficiency of the numerical algorithms without affecting their overall accuracy.

\section{Suggested values of error control tolerances}

None of the analyses presented failed to find a solution. Additional test runs suggest that the finite-element algorithms proposed in Part I are very robust, provided sensible error control tolerances are chosen. A great advantage of these algorithms is that their performance is not significantly influenced by the number of coarse steps defined by a user. Based on extensive tests runs on a wide range of practical problems subjected to various loading paths, the following values and conditions are suggested:

$$
\begin{aligned}
& \text { DTOL }=10^{-2}-10^{-4}, \quad \text { ITOL }=10^{-3}-10^{-5}, \quad \text { STOL }=10^{-4}-10^{-6}, \\
& \text { YTOL }=10^{-6}-10^{-9}, \\
& \text { DTOL } \geqslant \text { ITOL } \geqslant \text { STOL } \geqslant \text { YTOL }
\end{aligned}
$$

In practical applications of the finite-element algorithms, default values that satisfy the above

\begin{tabular}{|c|c|c|c|c|c|c|c|c|c|c|c|c|c|}
\hline \multirow[t]{2}{*}{ Tolerances } & \multicolumn{4}{|c|}{ CPU time (s) } & \multicolumn{4}{|c|}{ Total time substeps } & \multicolumn{4}{|c|}{$\begin{array}{l}\text { Max strain substeps } \\
\text { per time substep }\end{array}$} & \multirow[t]{2}{*}{$\begin{array}{c}\text { Final central } \\
\text { displacement (m) }\end{array}$} \\
\hline & Dry & Load & Wet & Exp. & Dry & Load & Wet & Exp. & Dry & Load & Wet & Exp. & \\
\hline $\begin{array}{l}\text { DTOL }=10^{-2} \\
\text { ITOL }=10^{-3}\end{array}$ & 480 & 111 & 65 & 131 & 391 & 100 & 100 & 117 & 1 & 1 & 175 & 246 & -0.0834 \\
\hline $\begin{array}{l}\text { DTOL }=10^{-2} \\
\text { ITOL }=10^{-4}\end{array}$ & 1277 & 112 & 119 & 414 & 872 & 100 & 100 & 216 & 1 & 1 & 178 & 210 & -0.0834 \\
\hline $\begin{array}{l}\text { DTOL }=10^{-3} \\
\text { ITOL }=10^{-4}\end{array}$ & 1351 & 111 & 118 & 400 & 936 & 100 & 100 & 213 & 1 & 1 & 177 & 205 & -0.0834 \\
\hline $\begin{array}{l}\text { DTOL }=10^{-3} \\
\text { ITOL }=10^{-5}\end{array}$ & 3240 & 107 & 176 & 894 & 2047 & 100 & 100 & 353 & 1 & 1 & 177 & 213 & -0.0834 \\
\hline $\begin{array}{l}\text { DTOL }=10^{-4} \\
\text { ITOL }=10^{-6}\end{array}$ & 6641 & 167 & 236 & 1731 & 3821 & 100 & 102 & 561 & 1 & 1 & 177 & 142 & -0.0834 \\
\hline
\end{tabular}
conditions can be set.

Table V. Numerical statistics for flexible footing problem. 


\section{CONCLUSIONS}

A number of practical problems involving unsaturated and saturated soils are analysed using the theory and algorithms developed in Part I. These problems include triaxial tests and strip footings that are subjected to a wide range of loading paths including drying, wetting, imposed displacements and pressure loading. The stress-strain constitutive equations are based upon the modified Cam clay model for saturated soils, with the preconsolidation pressure varying with suction. The soil-water characteristic equations follow those of van Genuchten [5] and Hillel [6], and the constitutive stress is defined in an alternative way so that both expansive and collapsible soils can be modelled.

The time and stress integration algorithms presented in Part I are shown to be accurate, robust and efficient for all the problems analysed. The efficiency of the algorithms, as measured by the CPU time consumed, is insensitive to the number of coarse time steps adopted but, as expected, is dependent on the error control tolerances specified. Provided sensible values are used, the accuracy and robustness of the algorithms are found to be insensitive to the number of coarse time steps. For the triaxial test problems, the numerical results agree well with the analytical solution based on the constitutive equations. For the footing problems, the numerical results appear reasonable in light of physical reasoning.

It is demonstrated that the constitutive modelling framework presented in Part I can, by adjusting one constitutive equation and one or two material parameters, be used to simulate both expansive soil that expands upon wetting and collapsible soil that shrinks upon wetting. Treating the suction as a strain variable instead of a stress variable proves to be an efficient and robust way of solving suction-dependent plastic yielding. Similarly, adopting the concept of a constitutive stress provides a seamless means of handling the transition between saturation and unsaturation.

\section{REFERENCES}

1. Sloan SW. Substepping schemes for the numerical integration of elastoplastic stress-strain relations. International Journal for Numerical Methods in Engineering 1987; 24:893-911.

2. Sloan SW, Abbo AJ, Sheng D. Refined explicit integration of elasto-plastic models with automatic error control. Engineering Computations 2001; 18:121-154.

3. Roscoe KH, Burland JB. On the generalised stress-strain behaviour of "wet" clay. Engineering Plasticity. Cambridge University Press: Cambridge, MA, 1968; 535-609.

4. Alonso EE, Gens A, Josa A. A constitutive model for partially saturated soils. Geotechnique 1990; 40:405-430.

5. Van Genuchten MT. A closed form equation of predicting the hydraulic conductivity of unsaturated soils. Soil Science of America Journal 1980; 44: 892-898.

6. Hillel D. Soil and Water-Physical Principles and Processes. Academic Press: New York, 1971.

7. Sheng D, Sloan SW, Yu HS. Aspects of finite element implementation of critical state models. Computational Mechanics 2000; 26(2):185-196.

8. Sheng D, Sloan SW, Gens A, Smith D. Finite element formulation and algorithms for unsaturated soils, Part I Theory. International Journal for Numerical and Analytical Methods in Geomechanics 2003; 27:745-765. 